\title{
Social competence and theory of mind understanding in elementary school children with attention deficits
}

\author{
Amy Wilson Strange \\ West Virginia University
}

Follow this and additional works at: https://researchrepository.wvu.edu/etd

\section{Recommended Citation}

Strange, Amy Wilson, "Social competence and theory of mind understanding in elementary school children with attention deficits" (1999). Graduate Theses, Dissertations, and Problem Reports. 3169. https://researchrepository.wvu.edu/etd/3169

This Dissertation is protected by copyright and/or related rights. It has been brought to you by the The Research Repository @ WVU with permission from the rights-holder(s). You are free to use this Dissertation in any way that is permitted by the copyright and related rights legislation that applies to your use. For other uses you must obtain permission from the rights-holder(s) directly, unless additional rights are indicated by a Creative Commons license in the record and/ or on the work itself. This Dissertation has been accepted for inclusion in WVU Graduate Theses, Dissertations, and Problem Reports collection by an authorized administrator of The Research Repository @ WVU.

For more information, please contact researchrepository@mail.wvu.edu. 
Social Competence and Theory of Mind Understanding in Elementary School Children with Attention Deficits

Amy Wilson Strange

Dissertation Submitted to the College of Human Resources and Education

at West Virginia University in partial fulfillment of the requirements

for the degree of

Doctor of Philosophy

in

Counseling Psychology

Michael T. Yura, Ph.D., Chair

Anne C. Watson, Ph.D.

Stanley H. Cohen, Ph.D.

Cynthia R. Kalodner, Ph.D.

Jeffrey K. Messing, Ph.D.

Department of Counseling, Rehabilitation Counseling, and Counseling Psychology

Morgantown, West Virginia

1999

Keywords: Theory of Mind, Attention Deficit Hyperactivity Disorder, Children, Social Skills Copyright 1999 Amy Wilson Strange 


\begin{abstract}
Social Competence and Theory of Mind Understanding in Elementary School Children with Attention Deficits
\end{abstract}

Amy Wilson Strange

The following study explored relations between theory of mind understanding, social competence, and auditory processing in elementary school children with and without Attention Deficit Hyperactivity Disorder. Children in this study were recruited from a local elementary school, as well as two outpatient clinics. Scores on measures of false belief and recursive thinking, social skills (Social Knowledge Interview, Harter, Emotion labels), and auditory processing (Test of Auditory Processing Skills, Revised) were obtained along with teacher ratings of children's self-regulation as measured by Attention and Hyperactivity subscales of the Conners' Teacher Rating Scale - Revised. Language ability was also measured using the Test for Comprehension of Auditory Language, Revised. Analyses indicated that children with and without ADHD differed significantly in their performance on all variables except the labeling of emotions, with ADHD children doing more poorly than their peers. Results also indicated that theory of mind understanding follows a developmental progression and that there is a positive relationship between false belief and recursive thinking tasks. A relationship between theory of mind understanding and social functioning in both groups was also found. Finally, regression analyses indicated that age, language ability, and auditory processing predicted performance on theory of mind, while hyperactivity predicted social competence. 


\section{TABLE OF CONTENTS}

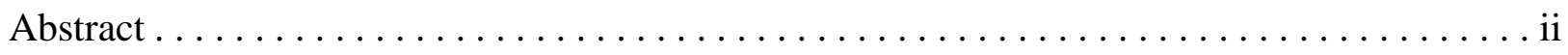

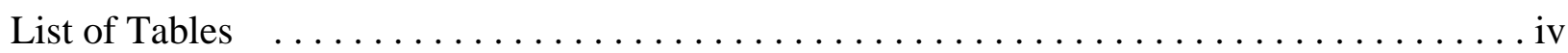

Acknowledgements $\ldots \ldots \ldots \ldots \ldots \ldots \ldots \ldots \ldots \ldots \ldots \ldots \ldots \ldots \ldots \ldots \ldots \ldots \ldots$

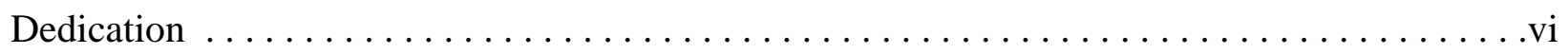

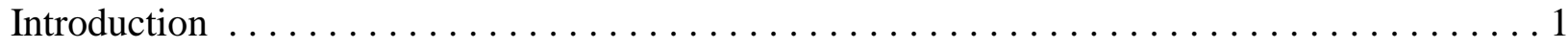

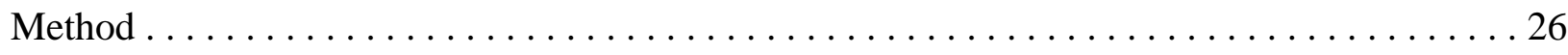

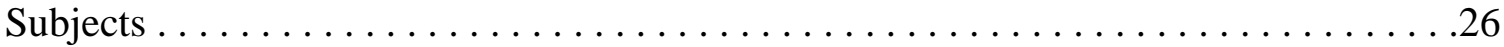

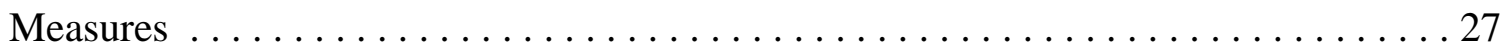

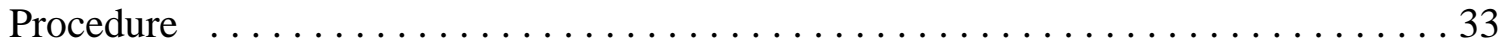

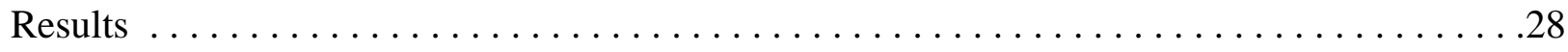

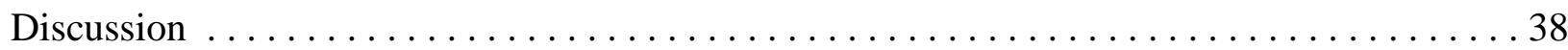

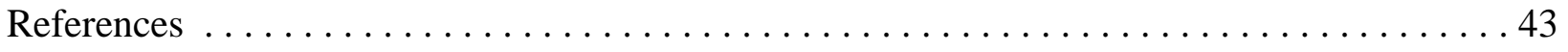


1. Mean, Standard Deviation, Range and $\underline{F}$ Scores for All Variables $\ldots \ldots \ldots \ldots \ldots 46$

2. Relations Between Theory of Mind and Social Skills $\ldots \ldots \ldots \ldots \ldots \ldots \ldots$

3. Correlations Between Theory of Mind, Social Skills, and Independent Variables ..... 48

4. Regression Analyses Predicting Theory of Mind and Social Competence in Children with ADHD .................................. 49

5. Regression Analyses Predicting Theory of Mind and Social Competence in

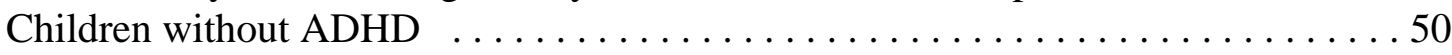

6. Regression Analyses Predicting Theory of Mind and Social Competence for Both Groups of Children ................................. 51 


\section{Acknowledgments}

I would like to express my sincere appreciation to my advisor and mentor, Michael T. Yura, for his unwavering support and encouragement over the past eight years. Thank you for sharing your love of children and for helping me understand myself better so that I could help others. I know I wouldn't be where I am today without you. I would also like to express my profound gratitude to Anne C. Watson, for her time, dedication, knowledge, and reassurance over the past four years as I attempted the ridiculous feat of completing two dissertations at the same time. I am particularly grateful for her willingness to "be there" at a seconds notice and for her encouragement at times when I thought I couldn't write another word. Thank you for being a teacher and a friend.

I would also like to thank the rest of my committee members, Cyndee Kalodner, Jeff Messing, and Stan Cohen for their time, knowledge, and support in this endeavor. I am deeply appreciative of the feedback they provided, as well as their willingness to adapt to my rather hectic schedule. I am also grateful for the time Jay and Pete spent collecting data for this project. An extra "thank you" to Dana Futoran who devoted many precious hours to data collection and

project development and whose enthusiasm was an inspiration. I am also particularly grateful to Dr. Charisse Linkie Nixon, my colleague and very dear friend, for providing me with endless comfort and faith, not to mention data.

I owe a great debt of thanks to the public school administrators who made this project possible, the parents who saw the value in this study, and of course the children themselves without whom greater knowledge is not possible.

I would like to especially thank my husband, Jeffrey Strange, for his motivation and support over the past year. Thank you for being interested in my work and keeping me going at times when I doubted myself the most. Without you this would have been far less fun!

Finally, I would like to thank my parents, Jim and Janet Wilson, for their unwavering encouragement during this long journey. Thank you for always letting me know that you were proud of me no matter how old I got or how long I was in school. 


\section{DEDICATION}

To my daughter, Megan Elizabeth whose little smile puts it all in perspective.

I love you! 


\section{Chapter 1: Introduction}

Over the past decade, a rising concern among educators, parents, and mental health professionals has been the increasing number of children diagnosed with Attention Deficit Hyperactivity Disorder, a developmental syndrome characterized by inattention, impulsivity, and hyperactivity (Barkley, 1998; Schwiebert, Sealander, \& Tollerud, 1995). Shaywitz and Shaywitz (1992) reported that ADHD represents one of the most frequently diagnosed disorders of childhood, with a prevalence rate of 3 to $5 \%$ in the elementary school population. These statistics also have relevance for adults as well since ADHD now appears to be a disorder that is present in some form for the whole of one's life (Phelan, 1993).

While the diagnostic and behavioral characteristics of ADHD may change slightly with the age of the individual, the negative impact of the disorder on one's functioning within society appears to remain constant. As many as 50\% of children with ADHD are estimated to have significant relationship difficulties, particularly a high rate of peer rejection (Milich \& Landau, 1982). Because of their characteristic behavioral symptoms, children with ADHD are often regarded as troublemakers, daydreamers, and at the very least nuisances, by peers, teachers, and parents, making it difficult to establish successful interpersonal relationships. This pattern continues into adolescence and adulthood as individuals with ADHD show trends toward increased alcohol and drug use, more antisocial behavior, less stable relationships, and a less successful work record when compared to their peers (Phelan, 1993; Weiss \& Hechtman, 1993).

A particular focus on the social functioning of individuals with ADHD is of importance because it is related to many other aspects of one's life. Work, mood, and academic performance may all be enhanced or impaired by one's relationships with others. For example, if teachers and peers view a child as disruptive, he or she is likely to receive less instructional help and support in school. At a basic level, this lack of assistance and encouragement could have a negative effect on the child's learning and future accomplishments which could then lead to a decrease in the child's self-esteem. Low self-esteem may in turn result in maladaptive behavior and social isolation. By examining such a cycle of failure, one can clearly see the potential for a series of events such as this to have a long-term impact on the individual's overall functioning. To date, social skills interventions aimed at addressing this issue have met with inconsistent success, possibly due to the ever-changing conceptualization of the disorder. 
Most recently, Barkley (1996b) described ADHD as a disorder of self-regulation, rather than one of over or understimulation, and hypothesized that many of the social problems experienced by children with ADHD are due to deficits in executive functioning and their inability to utilize socially relevant stimuli to control their behavior. This view of ADHD fits nicely with new perspectives on the development of social cognition which place more emphasis on individual differences in executive processes and is of particular interest in the present study which hopes to generate additional information for use in developing successful interventions with these children.

\section{History of ADHD}

Since the turn of the century, numerous diagnostic labels have been given to children who demonstrate significant deficits in sustained attention, impulse control, and regulation of activity level in response to situational demands. In the past, this constellation of symptoms has been referred to as "hyperkinesis," "hyperactive child syndrome," and "minimal brain dysfunction" (Barkley, 1989, 1998; Kelly \& Ramundo, 1992). Recently, this disorder was labeled "Attention Deficit/ Hyperactivity Disorder" (ADHD) in the fourth edition of the Diagnostic and Statistical Manual of Mental Disorders (DSM-IV; American Psychiatric Association, 1994). While at times confusing, the frequent relabeling associated with this syndrome reflects a continuously shifting emphasis on the primacy of certain symptoms within the disorder (i.e., hyperactivity, inattention), which drives diagnosis and treatment related issues.

The earliest acknowledgment of hyperactivity in children can be traced to several medical reports from the middle 1800's. These papers described children who had developed significant deficits in attention span coupled with an increase in hyperactive and impulsive behavior following their recovery from a central nervous system disease or injury (Ross \& Ross, 1982). However, attempts to conceptualize this constellation of symptoms as a disorder were not made until the turn of the century when George Still wrote about a group of 20 boys he had treated. As cited in Barkley (1998), Still described these boys as being "aggressive, defiant, resistant to discipline, and highly emotional with little self-control." He believed the problems these children manifested were the result of deficiencies in "volitional inhibition of behavior," as well as defects of moral control and claimed that because such children were deficient in their moral development, they did not possess the ability to control their own negative behaviors. Still's 
label of "Defect in Moral Control" makes clear his disregard of behavioral symptomology and his emphasis on the moral virtues of the time.

For the next fifty years, doctors and psychologists continued to find relations between brain disease or injury and the "holy trinity" of ADHD (attention, regulation of activity, and impulse control), as well as various other cognitive deficits (Barkley, 1998). By the late 1950's, research and medical reports seemed to clearly suggest a relationship between hyperactive behavior and brain injury or disease. Terms like "minimal brain damage" and "hyperkinetic impulse disorder" were used to identify these children and express a shift in emphasis from moral functioning to more biological/physiological factors.

Dissatisfied with these terms, many researchers in the 1960's conducted studies which pointed toward neurological mechanisms of involvement, rather than neurological damage, as an explanation of children's dysfunction. These individuals believed that many of these children were not brain damaged after all, but rather suffered from some form of brain dysfunction or abnormal processing of environmental stimuli. The term "minimal brain dysfunction" seemed to better describe the disorder at this time as individuals struggled to define "hyperactivity" as it related to these children (Barkley, 1998).

By the mid-1970's, further research indicated that most children who incurred a brain injury did not develop hyperactive behavior. These studies showed that less than $5 \%$ of hyperactive children demonstrated evidence of structural brain damage (Barkley, 1989; 1998). At this time, psychologists moved away from a concentration on physiology and began to consider the cognitive functioning of children with ADHD. As this occurred, the primary diagnostic criteria of the disorder became inattentiveness and impulse control problems and hyperactivity was viewed as a secondary symptom. This trend continued into the beginning of the 1980's, as the DSM-III was published and brought with it the diagnosis of "Attention Deficit Disorder (ADD) with or without Hyperactivity." The 1980's were a decade of developing and validating diagnostic criteria as psychologists and researchers attempted to better define this growing disorder. By the end of the decade, ADD had become Attention Deficit Hyperactivity Disorder once again, and a focus was placed on aspects of motivation, impairments in rulegoverned behavior, and social skills deficits, as psychopharmacological treatments continued to be the intervention of choice (Barkley, 1998). 
A focus on the genetic and neurological aspects of the disorder prevailed in the 1990's. Rather than blaming this disorder on bad parenting or too much sugar, evidence began to emerge which indicated that the brain functioning of children with ADHD was much different than that of their normal peers (Castellanos, Giedd, Eckburg, et. al., 1994). Studies of adults with ADHD were also more prevalent in this decade and pointed to the developmental nature of the disorder.

As the emphasis on symptoms of motor behavior continued to decline and the cognitive functioning of these children gained new importance, the etiology of the hyperactivity and inattention became of greater interest. Historically, it was believed that hyperactive children were somehow overstimulated (Barkley, 1998; Wenar, 1994). However, this theory of overarousal was difficult to explain in light of the effectiveness of stimulants such as Ritalin in controlling activity levels (Conners, 1966; Safer \& Krager, 1988). A more recent hypothesis is that the increased motor activity and inattentiveness observed in children diagnosed with ADHD is not the result of organic overstimulation, but a "deficiency in response inhibition and the capacity to delay responding" (Barkley, 1994; 1996a). This definition identifies ADHD as a complex disorder of not only behavior, but also cognitive processes of self-regulation and the cross-temporal organization of behavior involving several metacognitive abilities. Such a view highlights the role of executive functions that are influenced both by the environment and the individual organism. This theory also places a stronger emphasis on cognitive components and lends support to the recent conceptualization of ADHD as a disorder of stimulus control and motivation (Barkley, 1996b). This redefinition of ADHD as a disturbance in self-regulation and deficits in executive control, highlights the timeliness of the present study which incorporates the information processing and relationship difficulties of individuals with the disorder. Even though studies continue to explore the creation of treatment programs, many of which involve the use of medication (Abikoff \& Gittelman, 1985; Barkley, McMurray, Edelbrock, \& Robbins, 1989; Whalen, 1989) few studies have had as their primary focus the cognitive functioning of individuals diagnosed with ADHD nor have they provided conclusive strategies for improving the social relationships of these children. The present study hopes to address both of these issues in at least in some part. 


\section{The Developmental Pathway of ADHD}

As can be seen by examining its history, early work on ADHD focused primarily on behavioral symptoms exhibited by young children. It was not until recently that ADHD was considered a chronic disorder that continued into adulthood (Phelan, 1993). Because ADHD is not "curable," it is possible to follow the developmental pathway of the disorder over an individual's lifetime. Longitudinal and retrospective studies have enabled psychologists to discover that the symptoms of ADHD do in fact change over time for many individuals (Barkley, 1998; Weiss \& Hechtman, 1993), however relationship difficulties remain present at all stages of one's life.

Because behavioral symptoms of ADHD appear to arise in early childhood, with the average onset being between the ages of 3 and 4 years (Barkley, Fischer, Newby, \& Breen, 1988), little work with infants has been done in this area. There is some evidence to suggest that babies who are difficult to care for due to their high activity level, irritability, unpredictability, and inconsolability, are at risk for being labeled as hyperactive in childhood (Hartsough \& Lambert, 1985; Wenar, 1994). Additionally, anecdotal accounts have identified advanced motor activity (e.g., climbing out of the crib) in infants who were later diagnosed with ADHD in elementary school (Ross \& Ross, 1982). However, better predictors of a child developing the disorder include family history of ADHD, maternal health, family economic status, as well as the infant's overall health and development (Barkley, 1998; Hartsough \& Lambert, 1985; Nichols \& Chen, 1981; Palfrey, Levine, Walker, \& Sullivan, 1985).

More reliable indicators of ADHD occur as children enter the toddler years. Many experts believe that it is possible to identify 60-70\% of ADHD children by age two or three (Phelan, 1993). However, attention span and activity level are often not adequate markers of ADHD in toddlers since most 2-4 year-olds have sufficient problems with inattention to be of concern to parents and teachers (Barkley, 1998; Campbell, 1990). Instead, noncompliance, frequent attention switching, extreme stubbornness lack of long-term involvement in a task, and demands for significant amounts of attention from others are more indicative of ADHD in these early years (Wenar, 1994). Preschoolers with ADHD also tend to be moody, demanding, defiant, and may become injured at a higher rate when compared with normal peers due to their increased activity (Campbell, 1990). These children have been shown to be more aggressive and 
destructive in peer interactions, and are less responsive to physical punishment, reasoning, and persuasions by adults (Ross \& Ross, 1982).

By middle childhood (ages 5-12), the standards for self-control, task orientation, selfmonitoring of appropriate behavior, and cooperation in the family and peer group are sufficiently clear that the differences between normal variability in behavior and clinical levels are more readily apparent. Thus, a persistent constellation of behaviors (i.e., hyperactivity, inattention, impulsivity), may raise serious questions about psychopathology in certain children. In the early elementary school years, difficulty with school work, especially reading, may begin to emerge since a large percentage of children with ADHD also have a learning disability. In addition, at least half of the young children with ADHD will experience social rejection because of their intrusive, inept social behavior (Ross \& Ross, 1982). While some may develop feelings of low self-esteem and withdraw from social interactions, others will begin to view the world as a hostile place and become angry and aggressive toward others. During the elementary school years, at least 30 to $50 \%$ of children with ADHD will develop symptoms of conduct disorder (i.e., lying, cheating, fighting) and many will be placed on stimulant medication for the first time (Barkley, 1998).

The idea that the effects of ADHD are outgrown with age has come into serious question by several follow-up studies published in the last decade (Klein \& Mannuzza, 1991; Weiss \& Hechtman, 1993). Researchers have found that many individuals diagnosed as hyperactive in childhood continue to display behavioral symptoms and social difficulties to a significant degree in adolescence and young adulthood. In fact, Weiss \& Hechtman (1993) found that social functioning declines even further with age for some individuals with the disorder. It also appears that these individuals continue to have troubled relationships even when much of the impulsivity and hyperactive behavior associated with the disorder is absent (Phelan, 1993). In addition to their relational difficulties, individuals with ADHD also continue a trend of academic difficulties, as up to $58 \%$ of the adolescents were found to have failed at least one grade in school (Brown \& Borden, 1986) and adults with the disorder tend to suffer from poor work records even in the absence of an identified cognitive deficit. One reason for such failure may be the lack of environmental support for adolescents and adults with ADHD, suggesting the importance of a social network for adaptive functioning. 
By briefly exploring the developmental pathway of ADHD, one can immediately see the many far-reaching effects the disorder has on an individual's relationship to the environment and sense of self. Feelings of low self-worth, frequent misunderstandings with others, as well as difficulty completing tasks, are not uncommon among these individuals and negatively affect home, school, work, and peer relationships to a significant degree throughout one's lifetime (Hallowell \& Ratey, 1993; Weiss \& Hechtman, 1993). While it has not been established that poor peer interactions in childhood directly cause later relationship problems in adolescence and adulthood, it is plausible that the same factors contributing to these early social difficulties are responsible for maladjustment in later life.

\section{$\underline{\text { Social Functioning }}$}

Gresham \& Elliott (1987) have identified three commonly accepted definitions of social competence in the child behavior literature. The first definition emphasizes acceptance by peers, or popularity, as determining whether or not one possesses good social skills. For example, children who are liked by others are socially competent. While this explanation may be useful for identifying children who are accepted or rejected by peers, it does not delineate the particular skills necessary for acceptance and is thus of limited use in the development of successful social skills programs.

The second definition of social competence corrects this particular problem by focusing on actual behavior. This approach identifies adaptive social skills as those behaviors that are situationally specific in maximizing the probability of attaining reinforcement or decreasing the likelihood of receiving punishment. According to this definition sharing one's toys demonstrates social competence, while hitting another person does not. Even though this definition acknowledges the importance of antecedents and consequences of particular behaviors, it does not determine whether the behaviors hold enough social importance to be considered a skill necessary for positive interactions.

In the third definition, social competence is identified as situationally specific behaviors that predict outcomes which are prescribed by society. This definition provides a framework for identifying social competence based on its relation to socially desired outcomes, and proposes that such outcomes may differ depending on the situation and the judgment of others. It also takes developmental variables into consideration by identifying particular outcomes for different 
age groups. For example, we might expect a preschool child to react to conflict with tears and anger, while we would expect a child in the third grade to resolve a conflict by seeking help from a teacher. We determine the appropriateness of the behavior not only by the action, but the age of the individual as well. It is this definition that will serve as the basis of discussions of social competence in the present study.

It is widely accepted that children with ADHD have deficits in many areas of social functioning (Barkley, 1988). The inappropriate behaviors and poor social skills characteristic of many children with ADHD are commonly met with negative reactions by others in their environment (Campbell, 1990; Guevremont \& Dumas, 1994; Hubbard \& Newcomb, 1991). Investigations of the relationships of children with ADHD clearly demonstrate that when compared with their peers, these children have lower sociometric status on the average and are at a greater risk for social rejection (Flicek, 1992; Landau \& Moore, 1991; Pope, Bierman, \& Mumma, 1989; Wheeler \& Carlson, 1994). It is estimated that as many as 50 to $60 \%$ of children diagnosed with ADHD experience some form of social rejection during the elementary school years (Guevremont, 1990). Teachers often stereotype these children as being noncompliant and disruptive while parents may be worn down by their constant motion and emotional outbursts. Probably the most devastating of all is the reaction of peers who frequently see such children as troublemakers to avoid.

Several studies have demonstrated that not only are children with ADHD generally unpopular with their peers, but they may be at risk for rejection during their initial social interactions (Campbell, 1990; Erhardt \& Hinshaw, 1994; Hubbard \& Newcomb, 1991). From even their first contact with peers, children with ADHD are often ignored and mistreated by other children who speak to them less often and are more hesitant to engage them in reciprocal play (Brooks, 1994). This evidence further suggests that not only do these children have difficulty making friends, but they also often fail to maintain any relationships they are able to form. In addition, comparisons between ADHD/normal and normal/normal pairs show that dyads containing a child diagnosed with ADHD engage in lower levels of associative interaction, exhibit fewer signs of affective expression, and evidence less verbal reciprocity (Hubbard \& Newcomb, 1991). Studies utilizing sociometric ratings of children have also found that those diagnosed with ADHD are rarely nominated as someone with whom their peers would like to 
play, and are frequently labeled as undesirable playmates (Flicek, 1992; Guevremont \& Dumas, 1994; Pope, Bierman, \& Mumma, 1989).

As previously alluded to, it often appears to be the defining characteristics of the disorder (inattention, impulsivity, and hyperactivity) which present the greatest problems in social interactions for children with ADHD. When frustrated, an impulsive ADHD child may yell at others or even strike out physically without considering possible alternatives or the consequences of their action. Such impatient children have difficulty waiting their turn, blurt out answers in school, frequently lose things, interrupt others, shift from one activity to another, and have difficulty following rule-governed behavior. This continuous motion makes it impossible to interact with these children as they appear to be driven by a motor that does not tire. In fact, classroom observations suggest that hyperactive children are more active in a twenty-four hour period than their normal peers and demonstrate a greater amount of restlessness in the form of task-irrelevant movements, out-of-seat behavior, and squirming. Children with ADHD also have difficulty sustaining attention in the classroom, causing them to engage in more off-task than their normal peers.

Along with these three main diagnostic symptoms, children with ADHD may also demonstrate difficulty with delaying gratification, emotional overarousal (especially anger), and noncompliance (Barkley, 1998). These children consistently demonstrate difficulty with selfcontrol and emotion regulation, made worse by an absence of appropriate communication and play skills (Alessandri, 1992). They also tend to have a limited capacity to cope with social stressors and often regress to more primitive strategies of aggression and social withdrawal when faced with emotionally laden situations (Kennedy, Spence, \& Hensley, 1989).

Similar patterns of peer rejection and ineffective social functioning have been observed in adolescents and adults as well. Brown \& Borden (1986) found that as many as 25-35\% of the adolescents in their study of individuals with ADHD displayed antisocial behavior or symptoms of conduct disorder, both of which are highly correlated with peer rejection and social isolation. Additionally, many adults with ADHD report feeling isolated and lonely because it is difficult for them to maintain long-term relationships. Adults with ADHD also report feeling less satisfied with their intimate relationships when compared with their normal peers as indicated by a higher than average divorce rate (Klein \& Mannuzza, 1991). 
As with children, the interpersonal problems reported by adults with ADHD are often the result of maladaptive behavior patterns. Their bossiness, talkativeness, emotional lability, and tendency to complain make adults with ADHD unpleasant to be around (Hallowell \& Ratey, 1993). Some of these individuals may lose their friends or jobs due to their inattentiveness and inability to follow through with tasks, while others may have developed such low self-esteem that they simply choose to isolate themselves rather than face rejection. This is not to say that it is impossible for adolescents and adults with ADHD to develop satisfactory relationships. In fact, the ability to be outgoing, talkative, and energetic may be an asset to some who know how and when to utilize it. However, the pervasive, long-term rejection of children and adolescents is especially troubling since one of the strongest predictors of adult success is one's social status established in childhood (Phelan, 1993).

It is often easy to see why a causal link is assumed between the behavior of individuals with ADHD and their decreased social status. It is difficult for a child to make friends when he is "bouncing off the walls" or being aggressive toward others. Children are not going to want to play with a child who is pushy, defiant, and difficult to talk to. However, what is not clear is why relationship difficulties continue for most of these children even when many of the acting out behaviors they exhibit can be somewhat lessened with stimulant medications (Hinshaw, Burhmester, \& Heller, 1989). Studies and anecdotal accounts demonstrate that children who are taking Ritalin or other stimulant medication become less hyperactive and aggressive, but their social status remains the same (Buhrmester, Whalen, Henker, MacDonald, \& Hinshaw, 1992; Murphy, Pelham, \& Lang, 1992; Whalen \& Henker, 1985). Even more perplexing is why these relationship problems continue, or worsen, into adulthood when hyperactivity decreases considerably (Phelen, 1993; Weiss \& Hechtman, 1993). These data seem to indicate that hyperactivity and aggression are not the sole precipitators of negative social status and relationship difficulties for individuals with ADHD. Rather, there may be other factors with which they interact to create the serious problems individuals with ADHD experience as they attempt to develop and maintain interpersonal relationships throughout their lives.

\section{Social Cognition: The Importance of Attention and Auditory Processing}

To most people it may seem rather obvious why children with ADHD experience so much rejection. However, these children often have a difficult time understanding why others 
don't like them and may engage in behaviors which isolate them even further (e.g., interrupting peer play). Even though these children are among the most rejected by their peers, they often believe themselves to be socially competent (Hoza, Pelham, Milich, \& Pillow, et. al., 1993). In a study by Weiss \& Hechtman (1993), adolescents with ADHD were found to view themselves as equally fair, friendly, reliable, popular, and mature when compared with their peers. However, these same individuals also rated themselves as more disobedient, nervous, careless, inattentive, and aggressive than their normal peers. Such findings indicate that boys with ADHD believe they possess adequate skills (i.e., they think they are polite) for relating to others, however, they are still rejected by those around them. This incongruence between their perceptions of themselves and the way they are viewed by others may actually be the impetus for much of the frustration children and adolescents with ADHD report in social situations. It may be that the root of the relationship problems of children with ADHD is not their acting out behavior itself, but rather the way they process environmental stimuli which in turn drives their behavior.

In everyday interactions human beings must be information processors and problem solvers, however it appears that children with ADHD are less able to process what is going on around them in a manner that is conducive to positive social interactions. Children with ADHD are consistently unable to generate appropriate solutions to narrative situations, have difficulty problem solving in live interactions, and are also more likely than normal peers to view a situation in a negative way (Dodge, 1993; Joffe, Dobson, Fine, Marriage, \& Haley, 1990; Wheeler \& Carlson, 1994). It is not uncommon for children with ADHD to overinterpret the hostile intentions of others, causing them to become verbally or physically aggressive over minimal provocation (Milich \& Dodge, 1984).

In addition to differences in perspective taking, it is well-established that children with ADHD have difficulty sustaining attention to their surroundings (Hooks, Milich, \& Lorch, 1994). This is especially true for auditory stimuli as these children often struggle to attend to the speech of others, as in the case of lectures, conversations, or verbal directions (Phelan, 1993). These processing deficits may further compromise a child's social functioning because he or she may miss information that is vital to further positive interactions. In fact, a study by Pearson, Lane, \& Swanson (1991) suggests that the inability of children with ADHD to orient to auditory stimuli may underlie their social skill deficits. This study found that children with ADHD have 
difficulty attending to more complex stimuli much in the same way as young children. Thus, these children are less able to follow and participate in conversations, seriously impairing their ability to relate to others. While these studies lay the groundwork for a theoretical model of social competence based upon deficits in stimulus control and attention, further evidence of the important role of auditory processing in social functioning may be found in the cognitive psychology literature.

For well over a decade, Kenneth Dodge and his colleagues have extensively studied the relation between social cognition and aggressive behavior in children (Dodge, 1980, 1986, 1989; Dodge \& Frame, 1982). Stemming from this work, some of which has been longitudinal in nature, Dodge has identified three cognitive skills which are highly correlated with levels of aggressive behavior in children: (1) perspective taking, (2) empathy, and (3) problem solving ability (Dodge, 1986). In 1993, Dodge used these principles to develop a social informationprocessing model of aggression. In this model, he describes the four steps that are essential for adaptive social behavior: (1) interpreting cues, (2) generating responses to the cues, (3) choosing a response, and (4) acting and evaluating the responses. A key component to Dodge's model seems to be the child's ability to attend to social stimuli. First, if a child has a decreased capacity to attend to stimuli in his environment, he will be unable to accurately interpret cues necessary for positive social interactions. This child must rely on previous experience, which may also be incomplete, to guide his behavior. Because of this lack of knowledge, such a child would also have difficulty generating and choosing appropriate responses as well as evaluating his behavior. Inattention may also affect response generation and implementation because both of these tasks require continued attention to the environment.

The relationship between social cognition and attention has been further examined in the ADHD literature. Barkley (1998) has identified three cognitive factors that may affect a child's ability to accurately problem solve in social situations: (1) communication skills; (2) perceived locus of control; and (3. processing of relevant stimuli/stimulus control. Children with ADHD have been found to talk more but to be less efficient in communicating information to peers (Clark, Cheyne, Cunningham, \& Siegel, 1988; Whalen, Henker, Collins, McAuliffe, \& Vaux, 1979). Despite talking more, ADHD children are less likely to respond to questions posed by peers and demonstrate less reciprocity in their social interactions (Cunningham \& Siegel, 1987; 
Landau \& Milich, 1988). Research findings also suggest that when compared with their peers, children with ADHD have a more external locus of control (Linn \& Hodge, 1982). These children are more likely to view most situations as being largely out of their control which may lead them to blame others for their problems or even for their behavior itself. Finally, because of their inattentiveness and impulsivity, children with ADHD are ineffective at processing environmental stimuli. Not only do they "misread" cues as previously mentioned, but they also miss stimuli altogether. The result is that these individuals are lacking information necessary for adaptive social relationships. Even though children with ADHD consistently demonstrate deficits in all three areas, it is their ineffectiveness in utilizing socially relevant stimuli to guide their behavior which is of most interest in the present study.

\section{Theory of Mind: False Belief and Recursive Thinking}

A central component of human social interaction is the ability to understand that individuals can have different perspectives of any given situation. In order to function successfully in social interactions, it has been suggested that individuals must attend to what others think, feel, and see, and be able to compare and contrast different perspectives, including their own, as they attempt to ascertain the intentions of others around them (Chandler, 1977; Shatz, Wellman, \& Silber, 1983). An individual with a well-developed mentalistic theory of behavior is able to accurately interpret intentional action as well as predict and explain behavior. In the cognitive psychology literature, such an ability is called theory of mind (Chandler, Fritz, \& Hala, 1989; Gopnik, 1993; Perner, Ruffman, \& Leekam, 1994).

The beginnings of a theory of mind can be seen in the understanding of false beliefs (Perner \& Wimmer, 1985). In order to predict the behavior of others, children must rely upon multiple sources of information. They must have a working knowledge about their past, present, and future environment and the behavior of others in it. In addition, children must also attend to regularities in the behavior of themselves and others if they are able to predict future actions. An awareness of false belief involves understanding that the self and others can have internal representations that are different from reality and from each other (Gopnik, 1993). In order to predict behaviors that are linked with false thoughts, the individual must rely upon multiple sources of information, in particular, information about not only the current environment and current behavior, but also the past environment and past behavior. If a child is asked whether or 
not a peer knows about a falsehood, that child must have some knowledge of the peer's past behavior and knowledge. Successful performance on a false belief task includes a demonstration of the understanding that thoughts may not match reality, and that the knowledge states of another may not correspond with one's own. For example, Sarah is told that a Bandaid box currently contains crayons instead of bandaids. She is then asked where her friend Mark would look if he cut his knee and needed a bandaid. If Sarah has developed an understanding of false beliefs, she will respond that Mark will look in the Bandaid box, because boxes with pictures of bandaids on them usually contain bandaids and not crayons. If Sarah's understanding of false beliefs and her ability to consider and reason about the perspective of another is not yet welldeveloped, she will say that Mark will look elsewhere for a bandaid because the Bandaid box contains crayons. She will answer the question based upon her perspective, not Mark's.

The ability to problem solve and draw conclusions about behavior based upon false beliefs emerges in the preschool years around age 4 (Astington, 1991). It is considered a critical turning point in social cognition because it signals the child's understanding that behavior is to be explained not just by the present, observable environment, but by past and future events as well. Once a child has an understanding of the representational aspects of thinking and believing, more complex capabilities become possible. One example of this is an individual's ability to reason about another's embedded thoughts (Eliot, Lovell, Dayton, \& McGrady, 1979; Oppenheimer, 1986; Veith, 1980), also known as recursive thinking. Like false belief understanding, recursive thinking involves the ability to take the role of another person, however, these tasks require the additional ability to utilize a mental model of two or more individuals' beliefs about each other (e.g., Tim thinks that Janet thinks that he thinks she is angry).

While extensive research has been conducted on the emergence of a sophisticated understanding of "the mind" (Astington, 1993, Gopnik \& Slaughter, 1991), links between the development of a mentalistic theory of behavior and social competence in normal children have just begun. Studies of autistic children have shown that these individuals often fail false belief tasks because they do not attribute mental states to others. In fact, they are significantly less competent at understanding mentalistic constructs when compared with their normal peers (Baron-Cohen, Leslie \& Frith, 1985; Tager-Fulsberg \& Sullivan, 1994). A more recent study has also established a relationship between the understanding of false beliefs and non-clinical levels 
of aggression in preschoolers (Capage \& Watson, under review). In this study, children who scored lower on false belief tasks demonstrated significantly more aggressive behaviors toward peers as measured by teacher report. Other aspects of children's early social interactions have also been correlated with false belief understanding. Astington \& Jenkins (1995) found that preschoolers who had the highest scores on false belief measures were more likely to make joint proposals (e.g., let's feed the baby) and explicit role assignments (e.g., you be the mommy) to themselves and others during sessions of pretend play. Watson, Nixon, Wilson, \& Capage (1999) found that false belief understanding was positively correlated with teacher ratings of prosocial behavior in preschool children, thus establishing an initial link between theory of mind and social functioning.

Research on theory of mind and recursive thinking pre-supposes that understanding the intentions and thoughts of others at any level is a complex process which involves three steps: (1) attending to behavior and the impact that the environment has on behavior, (2) taking into account past events, and (3) making predictions about future events (Perner, Ruffman, \& Leekam, 1994). Deficits in any one of these steps may result in faulty assumptions about another's behavior, which could lead to negative social interactions. For example, if a child is unable to attend appropriately during a conversation with others, he or she may miss information that is vital to further positive interactions. The result of this miscue may be seen in clinical populations where children with acting out problems are overtly rejected by their peers, while those with attention problems are more often overlooked, a subtle form of rejection (Barkley, 1990).

\section{Clinical Implications}

One reason for attempting to better understand the social skills deficits of individuals diagnosed with ADHD is so that the long-term negative impact of relationship difficulties may be lessened. In order to accomplish this goal, effective intervention programs must be developed. To date, social skills interventions for children with disruptive behavior disorders have received inadequate research attention given their magnitude and possible consequences on society (Guevremont \& Dumas, 1994). There are many cognitive-behavioral treatments for children with ADHD which cover everything from appropriate classroom behavior to basic skills for positive social interactions (Barkley, 1991). Most of these programs report at least some 
short-term success in teaching children appropriate social skills. However, when faced with "real life" situations, especially those involving anger and conflict, the ability of these children to react appropriately appears to decline (Abikoff, 1991).

One explanation for this may be that even though these children are learning socially appropriate behaviors, they are doing so in such a sterile setting (e.g., a counselor's office) that generalization to novel situations is difficult to obtain. This may be particularly true when ADHD children are under increased amounts of stress and distraction. This lack of generalization may also be due to the theoretical basis of many interventions. The majority of social skills training programs utilize basic principles of operant conditioning to eliminate negative behaviors and teach ones that are more adaptive (Hinshaw \& Melnick, 1992). In many cases, specific cues and reinforcers are used to shape responses, thereby providing children with structured prompts to guide their behavior. However, when these cues are not present, it is more likely that the new behaviors will extinguish. For example, a child with ADHD might learn that when a teacher puts her hand in the air the child is to be quiet. However, another teacher may not use this signal and without a prompt, the child may regress to less appropriate behaviors.

Another reason for the limited success of such behaviorally based programs may be that they are not addressing the basic cognitive abilities necessary for positive social interactions. Studies have determined that children with ADHD demonstrate deficiencies in their self-talk and narrative generation (Berk, \& Potts, 1991; Tannock, Purvis, \& Schachar, 1993). Dodge and his colleagues $(1983 ; 1993)$ have also shown that conduct disordered and hyperactive children are less able to accurately process social information. These information processing and production deficits, alone or in combination, may make it very difficult for a child with ADHD to accurately perceive what is going on around him or her and respond appropriately. In light of such findings, social skills training programs may want to target improvement of the social cognition skills and perspective taking abilities that appear to be critical for successful interactions with others.

\section{Statement of the Problem}

Currently, 3 to $5 \%$ of the elementary school age population is diagnosed as having Attention Deficit Hyperactivity Disorder (Kauffman, 1993). Schools constantly struggle with how to best serve the needs of these children. Parents are concerned about the inability of their children to form meaningful relationships and the impact this has on other aspects of functioning 
(Campbell, 1990; Hubbard \& Newcomb, 1991). It has also become increasingly evident in the past decade that the relationship difficulties of individuals with ADHD continue to have a profound effect on many facets of their lives well into adulthood (Hallowell \& Ratey, 1993; Phelan, 1993; Weiss \& Hechtman, 1993).

Studies have shown that children with ADHD suffer from an increased risk for rejection by peers, parents, and teachers, and that this rejection is closely tied to deficits in the development of appropriate social responding (Flicek, 1992; Landau \& Moore, 1991; Wheeler \& Carlson, 1994). These children appear to be more active and aggressive than their normal peers, and have less well-developed communication, problem solving, and self-control skills (Alessandri, 1992; Frederick \& Olmi, 1994). Currently, there are various interventions which aim to improve the social skills of individuals with ADHD and related disorders (see Barkley, 1998 for review). Unfortunately many of these programs fall short of their desired goal: to improve the behavior and social status of children with disruptive behavior disorders. Interventions that incorporate the use of medication are able to decrease acting out behaviors (e.g., hyperactivity), but are less effective in improving the overall social functioning of these children (Buhrmester, et. al., 1992; Murphy, Pelham, \& Lang, 1992; Pelham, et. al., 1991). Cognitive-behavioral programs address this shortcoming by teaching children specific social skills, however generalization of the new behavior from the learning environment is poor (Barkley, 1998; Hinshaw \& Melnick, 1992; Kolko, Loar, \& Sturnick, 1990; Gordon, Thomason, Cooper, \& Ivers, 1991).

Even after taking stimulant medication or participating in social skills training, many children with ADHD continue to have difficulty in their relationships with others. It has been hypothesized that the root of the social problems experienced by individuals with ADHD is their difficulty utilizing socially relevant stimuli to control their behavior (Barkley, 1998). It is believed that these children are less able to attend to environmental cues necessary for relating to others in an adaptive manner. It appears that children with disorders of attention are capable of learning to attend to and respond appropriately to environmental cues in a sterile setting (e.g., counselor's office), but they have difficulty generalizing stimulus control to new situations. This may be particularly true when they are under increased amounts of stress and distraction. 
One explanation for a lack of stimulus control may be that the core of their social deficits is not acting out behavior, but the way they process stimuli in their environment. Research seems to indicate that individuals with ADHD evidence distinct differences in brain functioning when compared with their normal peers which results in an impaired ability to attend to environmental stimuli. Deficits in stimulus detection then lead to identified processing differences/deficits which may in turn lead to a decreased capacity for environmental stimuli to control behavior. The ultimate result is poor social skills and impaired relationships which may then contribute to low self-esteem, school failure, and so on. In other words, it appears that children with attention deficits are less able to attend to and process environmental stimuli, particularly auditory cues, in a manner that is conducive to positive social interactions. A lack of attention to environmental stimuli may result in an inability to access information critical to the development of an understanding of others' beliefs and intentions. In light of this information, social skills training programs may want to target improvement of social cognitive skills and theory of mind understanding that appear to be critical for successfully interacting with others. Before such programs can be created, research into the relation between complex executive processes and their impact on social functioning must be investigated. The present study will address this issue by exploring the relation between ADHD, theory of mind understanding, auditory processing, and social competence in elementary school children.

\section{The Present Study}

One of the most pervasive problems suffered by children with ADHD is social rejection. Research has clearly identified many of the behaviors that contribute to this rejection (e.g., overactivity and aggression), but has offered little in the way of an explanation for why this rejection persists even when these behaviors are absent. One possibility may lie in the cognitive processing abilities of these individuals. It may be that children with ADHD are unable to accurately perceive and interpret the beliefs and actions of others and therefore make faulty assumptions which lead to maladaptive social behavior. The purpose of the present study is to examine the relation between theory of mind understanding, auditory processing, and social competence in children diagnosed with ADHD and their normal peers. Four research questions will be considered in this study. 


\section{$\underline{\text { Research Questions }}$}

First, is there a relationship between false belief understanding and the ability to reason about another person's embedded thoughts (recursive thinking)? Both tasks require an individual to utilize a mental model to interpret another's beliefs, however, because both of these tasks have never been used in the same study, their exact relationship to one another is unclear. The use of both measures also allows for the study of a broader age range than is found in traditional theory of mind studies. While false belief tasks have been most commonly used with younger children (preschool) and recursive thinking tasks used with older subjects, the inclusion of both tasks in one study may provide a better understanding of the developmental progression of theory of mind comprehension in children. It is hypothesized that all children will do less well on the more complex recursive thinking task, and that older children will perform better than younger ones as tasks become more complex.

Second, do children diagnosed with ADHD evidence less theory of mind understanding and social competence when compared with their peers? In order to answer this question, the researcher will investigate whether children with ADHD develop adequate perspective taking skills by measuring their understanding of false beliefs and second order thinking. Scores for children diagnosed with ADHD will then be compared with those of their normal peers. It is expected that children with ADHD will perform more poorly on theory of mind tasks when compared with their normal peers.

Third, is there a relationship between social functioning and theory of mind in children diagnosed with ADHD? To answer this question, scores on theory of mind tasks will be compared to scores on various measures of social competence. Teachers will be asked to report on children's social functioning by means of a rating scale questionnaire (Harter), while a more direct sample of children's abilities will be obtained by use of the Social Knowledge Interview (Asher \& Renshaw, 1981) and an emotion labeling task. Age and language ability will also be controlled for in the analyses.

Finally, the social cognition literature seems to indicate that attention and auditory processing are key components to theory of mind understanding and social functioning. The present study will consider this relationship by exploring the influence of age, language ability, stimulus control, and auditory processing on theory of mind understanding and social 
competence. It is expected that children who evidence stimulus control and auditory processing deficits will do less well on theory of mind, as well as be less socially competent. It is also expected that auditory processing and stimulus control will account for a unique amount of variability in behavior beyond that of age and language. In order to examine these hypotheses, scores on the Test of Auditory-Perceptual Skills, Revised, TACL-R, and Conners will be compared with children's scores on theory of mind tasks and measures of their social competence.

Because verbal aptitude has been shown to be related to a child's theory of mind understanding, steps will be taken to control for language ability in this study. In addition to modifications in recursive thinking tasks (children will point to stimuli rather than be required to generate verbal responses), participants will be given the Test for Auditory Comprehension of Language, Revised (TACL-R) as a control measure.

\section{Chapter 2: Method}

\section{$\underline{\text { Participants }}$}

The present study consists of sixty-three subjects (thirty-one with ADHD and thirty-two without the disorder) and was completed in conjunction with this author's first dissertation in Developmental Psychology (Wilson, Watson, \& Yura, in preparation). That is, all children were given measures for both studies, decreasing the total number of subjects needing to be recruited by this examiner. Subjects were initially recruited from grades K-3 at an elementary school in Morgantown, WV. Permission to conduct this study was obtained from the West Virginia University Institutional Review Board, as well as from the principal of the elementary school in which data was being collected and the Monongalia County Board of Education. A letter was sent to all kindergarten, first, second, and third grade teachers in the school briefly describing the study and asking for their cooperation. Letters were also sent home with children in these four grades asking for parental permission to participate in the project and whether or not the child has been diagnosed with ADHD. Only those children with signed permission forms could be in the study.

A total of sixty-two children without ADHD and fourteen children with the disorder were able to be recruited from the school population. Because of the low number of ADHD children available for participation in the study, the other seventeen ADHD subjects were recruited from 
an outpatient clinic in Clarksburg, WV (12) and a day program in Erie, PA (5). Parental permission was obtained for these children as well, and parents were asked to enlist teachers to fill out the Harter and Conners. Only those children who completed all measures and did not evidence any comorbidity (i.e., Conduct Disorder, Depression) were used in final analyses. This resulted in a set of thirty-one children with ADHD and a matching set of thirty-two non-ADHD subjects. The non-ADHD group was matched to the ADHD group by gender and age of the children. Additionally, in order to provide as much consistency as possible between the different settings, all clinic children were tested during school hours and did not have to wait more than five minutes after arriving at the clinic to see the examiner.

Children in the study were 5 to 10 -years-old, and from predominantly white middle class families. There was not a significant difference between the age of the children with ADHD $($ mean $=99$ months $)$ and those without the disorder $($ mean $=96$ months $)(\underline{t}=1.13, \underline{p}=.136)$ or between males $($ mean $=99$ months $)$ and females $($ mean $=95$ months $)(\underline{t}=1.36, \underline{p}=.178)$. However, there was a significant difference between the age of children recruited from the school $($ mean $=94$ months $)$ and those tested in the clinics (mean $=107$ months $)(\underline{t}=-3.79, \underline{p}<.01)$. All of the children diagnosed with ADHD were taking stimulant medication at the time of data collection and were therefore receiving some type of therapy. Additionally, all children included in the study were judged via clinical interview to be verbal and of at least low average intelligence.

\section{$\underline{\text { Measures and Procedures }}$}

For the present study, both teacher report and direct child measures were used to obtain data about children's classroom behavior, auditory processing, language ability, social competence, and theory of mind understanding.

\section{$\underline{\text { Measure of Stimulus Control }}$}

Conners' Teacher Rating Scale - Revised Teachers completed a measure of children's behavior that included subscales of attention, conduct problems, and hyperactivity. The revised Conners' Teacher Rating Scale, short form (CTRS-R:S) includes 28 questions which provide information about children's classroom behavior. Teachers rated each question on a Likert type scale according to how much of a problem it had been for the child in the past month: 0 -"Not true at all" (never, seldom); 1 - "Just a little true" (occasionally); 2 - "Pretty much true" (often, 
quite a bit); 3 - "Very much true" (very often, very frequently). The internal reliability of the CTRS- R:S has been found to be quite high with total reliability coefficients ranging from .88 to .95 (Conners, 1997). Test-retest reliability is also adequate ranging from .72 on the Hyperactivity factor to .92 on the Cognitive Problems factor. Previous versions of the CTRS were also found to have adequate test-retest reliability at one month, .72 to .92 (Conners, 1973) and one year, .35 to .57 (Trites, Blouin, Ferguson, \& Lynch, 1981). Studies have also found adequate criterionrelated validity, including convergent and discriminant validity, for the CTRS-R:S. For the purpose of the present study, standard scores were tabulated for the Attention and Hyperactivity subscales as it was hypothesized that these specific self-regulatory factors might be most crucial to theory of mind understanding.

\section{Measure of Auditory Processing and Reasoning}

Test of Auditory-Perceptual Skills, Revised The Test of Auditory-Perceptual Skills, Revised (TAPS-R) can be used with children ages 4 to 13 and measures auditory word discrimination, number memory, word memory, sentence memory, interpretation of directions, and auditory processing (Gardner, 1997). The battery of subtests included in the TAPS-R can be administered in 15 to 25 minutes depending on the age of the child. Items on the TAPS-R are arranged from easiest to more difficult. The reliability of the TAPS-R was established by examining the internal consistency of the subtests and the test as a whole. Reliabilities were calculated using Kuder-Richardson formula 21, with coefficients on the total test scores ranging from .69 to .75 . Content, item, diagnostic, and criterion-referenced validity were examined for the TAPS-R and established the TAPS-R as a valid instrument for assessing auditory perception abilities.

\section{Measures of Theory of Mind}

The present study utilized three measures of theory of mind understanding in the form of false belief and recursive thinking tasks. The inclusion of multiple theory of mind measures in a single study is a major contribution to the exploration of individual differences in this area as it provides new information about the developmental progression of specific types of thinking that are an integral part of theory of mind acquisition.

False Belief Tasks False belief tasks assess a child's ability to predict and explain behavior (Bartsch \& Wellman, 1989). The two false belief tasks used in this study were adapted 
from previous research (Astington \& Gopnik, 1988; Bartsch \& Wellman, 1989; Lalonde \& Chandler, 1995; Lewis \& Osborne, 1990; Wimmer \& Perner, 1983). However, as the present study is one of the first to use these measures to examine individual differences in theory of mind understanding, the specific versions of the tasks used in this study have not been standardized which is keeping with the normal standard of practice in this area of research.

Chocolate Task For the first false belief task, a child was shown two dolls, Max and his mom. The experimenter told a story about Max and his mom returning home from a shopping trip with some chocolate. The experimenter told the child that mother put the chocolate in the blue drawer of a small, pink cupboard. The experimenter then put a Hershey's kiss into the blue drawer. As the story continues, Max leaves the room and during his absence, his mother moves the chocolate from the blue drawer to the green drawer in the cupboard. The experimenter then moved the candy to the green drawer. Later in the story, Max returns to the kitchen to look for the candy. The child was then asked a series of two questions to measure comprehension of the story: "Where did the chocolate used to be?" and "Where is the candy right now?" A second set of questions were asked to assess the child's false belief knowledge. The first question was "Where will Max think the chocolate is when he comes back?" If the child responded "the blue drawer," then he or she correctly predicted the doll's thoughts, demonstrating an understanding that others can have incorrect beliefs, and was given one point. The child was then asked, "Where will Max first look for the candy?" If he or she again responded "the blue drawer," an understanding of false belief was demonstrated and one point was recorded. This task took approximately 5 to 10 minutes to administer.

Bandaid Box. For the second task, each child was presented with a bandaid box and asked, "Do you know what is in here?" The child was then shown that a car was inside of the box. Next, he or she was asked, "What did you think was inside this box?" If the child responded that there were bandaids in the box, he or she recognized an ability to have beliefs which are untrue, and two points were recorded. If the child's response was that the box contained bandaids, he or she was asked, "What did you think was inside this box before I opened it?" If he or she answered correctly ("bandaids") then one point was recorded. A zero was given if the child failed to demonstrate any false belief under-standing (i.e., continued answering that he or she thought there was a car in the bandaid box originally). 
In the second phase of this task, the child was presented with a crayon box and shown that it contained bandaids. A doll named Pam was introduced and the child was told that she had cut her finger and needed a bandaid. The experimenter then asked the child, "Where will Pam look for bandaids?" If the child answered "the bandaid box," one point was recorded for correct false belief understanding. If the child's reply was "the crayon box," zero points were recorded and the child was asked the following questions: "Will she find bandaids there? What will she find?"

In the final phase of this task, the child was introduced to a doll named Bill who had a cut. The experimenter then showed Bill looking in the bandaid box and asked the child "Why is he looking in there?" Two points were recorded if the child's reply included a statement about Bill thinking that the box contained bandaids. One point was recorded for responses that described the box, but did not make reference to Bill's thoughts (e.g., "it has bandaids in it"). This task also took approximately 5 to 10 minutes to administer.

Total possible scores ranged from 0 to 5 on the bandaid box task and from 0 to 2 on the chocolate task. Even though the range of possible scores is rather narrow, previous research has found that preschool children show reliable individual differences in their performance on these tasks (e.g., Astington, 1991; Watson, et. al., 1999). This same trend was expected in the present study since some younger children were included and children with ADHD were expected to exhibit significant deficits in theory of mind understanding.

Recursive Thinking Task The more complex recursive thinking task utilized thought bubbles to capture a child's ability to reason about embedded thoughts. Once again, because this was one of the first studies to use this task with the present population, there was no information available about the reliability and validity of the measure. Miller, Kessel, and Flavell (1970) determined that children's understanding of recursive, or embedded, thinking emerges during middle childhood. They further argued that this understanding develops sequentially across four types of thinking: a) thinking about people as social objects; b) thinking about actions between people; c) thinking about thinking (one-loop recursion); d) thinking about thinking about thinking (two-loop recursion). In this early study, children were shown cartoon drawings that included thought bubbles and asked to interpret their contents. Results indicated a positive correlation between age and the ability to understand embedded thoughts at these four levels, 
thus supporting the hypothesis that knowledge of recursive thinking develops in sequential stages that are related to chronological age. Veith (1980) supported Miller, et. al.'s findings in a study which found that fifth graders were significantly superior to third graders in thinking about a social nonrecursive act, one-loop recursion, and two-loop recursion. These developmental data suggest the possibility of individual differences in performance on this task which would tap into the sophistication of a mentalistic theory of behavior.

One criticism of Miller, Kessel, and Flavell's 1970 study of recursive thinking was that it required an advanced level of verbal production. Oppenheimer (1985) addressed this issue by changing Miller, et. al.'s paradigm slightly. Instead of asking children to describe a picture, he presented them with a set of picture cards and asked them to point to a specific one (e.g., "show me the picture of the boy thinking that the girl is thinking about him"). This procedure resulted in kindergartners evidencing the possession of contiguity thinking and the onset of action thinking and one-loop recursive thinking. Third graders in this study demonstrated early signs of an understanding of two-loop recursive thinking as well. These findings place the onset of understanding one-loop and two-loop recursive thinking two years earlier than those suggested by Miller, et. al. and were used as a model for the recursive thinking tasks in the present study. For this study, it was first determined whether or not children understood the difference between thinking and talking by presenting them with stimulus cards of both actions and clarifying the difference if necessary. They were then presented with cartoon pictures of boys and/or girls with thought clouds depicting the 4 types of thinking previously mentioned, contiguity, action, one-loop, and two loop. Contiguity involves an individual thinking about himself or others (e.g., the boy is thinking of himself and the girl). Action thoughts involve thinking about one individual talking to another (e.g., the boy is thinking that the girl is talking to her father). One-loop recursion involves thinking about another person's thought processes (e.g., the boy is thinking that the girl is thinking of her father). Finally, two-loop recursion involves more in-depth perceptions of another person's thought processes (e.g., the boy is thinking that the girl is thinking of the father thinking of the mother). An array of eighteen cards were presented and the child was asked to point to a specific one (e.g., "show me the picture of the boy thinking of the girl talking to the father"). Responses were scored as a 1 if correct and a 0 if incorrect, for a total of 18 possible points. This task took approximately 10 minutes to complete. 


\section{Measures of Social Functioning}

Teachers' Ratings of Children's Social Behavior A measure adapted from the Perceived Competence Scale for Children (Harter, 1979) was used to assess teachers' perceptions of children's social skills. This ten-item measure asks teachers to rate a child's social behavior on a 4-point scale. For each item, the rater is presented with two statements about the child and asked to indicate which statement is either "really true" or "sort of true" for the child (e.g., This child finds it hard to make friends or This child finds it easy to make friends). A social competence score ranging from 7-28 was derived from teachers' responses on the first seven items of the questionnaire. A higher score is indicative of greater social competence, while a lower score indicates deficits in social functioning. Scores on this measure have been found to be stable across time, as well as across raters (Eisenberg, Fabes, Bernzweig, et. al., 1993).

Emotion Labels This task assesses individuals' ability to generate emotion and feeling state labels for a series of pictures and was used to determine children's ability to accurately read emotions on a visual level. Each child was presented with 12 different photographs of individual, unfamiliar children and asked the question, "How is this child feeling?" (adapted from Cassidy, Parke, Burkovsky, \& Braungart, 1992). Pictures were presented one at a time. A child's score on this task is the number of emotions correctly identified for a possible total score of 0 to 12 . The correctness of responses was determined by having approximately 60 college undergraduates label the faces and then using the top 3 answers for each one. The task took approximately 5 minutes to administer.

Social Problem Solving An adaptation of the Social Knowledge Interview (Asher \& Renshaw, 1981) was used as a measure of social competence. The version of the interview used for this study consisted of four social problems representing three types of problem situations: initiating social interaction, maintaining social interaction, and managing conflict. Children were given the instruction, "I want you to imagine this situation" and then a social scenario containing setting information and an initiating event was read to them. Following each situation, children were asked, "What would you do in this situation?" After their initial response was recorded, they were asked, "Would you do anything else?" Responses on the SKI were scored on a 5-point Likert scale according to the degree to which the response was considered socially appropriate for the situation. A rating of 1 for a response means that most people would find it extremely 
socially inappropriate given the situation. A score of 3 for a response means that it is one which most people would consider somewhat appropriate. A score of 5 indicates that the response is one which would be considered socially appropriate by most people. Scores of 2 and 4 would fall in-between these scores. A total of four scenes were read to each child, yielding a total score ranging from 4 to 20 . The measure took approximately 10 minutes to administer.

\section{Measure of Language Development (covariate)}

Test for Auditory Comprehension of Language, Revised (TACL-R) The TACL-R assesses receptive language functioning in children between the ages of 3 years, 0 months and 9 years, 11 months (Carrow-Woolfolk, 1985). The TACL-R was standardized on a diverse sample of 1,003 children and found to be highly reliable as a measure of receptive language functioning in children. Test-retest reliability ranged from .89 to .91 for the subtests, and was .95 for the total test. Additionally, the TACL-R has satisfactory concurrent and content validity (Sattler, 1992). The TACL-R is divided into three 40-item subtests: (a) Word Classes and Relations (knowledge of vocabulary), (b) Grammatical Morphemes (knowledge of grammar), and (c) Elaborated Sentences (comprehension of complex sentences). The TACL-R was administered to each child according to the procedures presented in the TACL-R Examiner's Manual (1985) and took approximately 15 minutes. During each subtest item, the experimenter presented the child with a series of three pictures and a verbal prompt, such as a word, phrase, or sentence. The experimenter then asked the participant to point to the picture that corresponds with the prompt. The percentile rank for each child was used as a measure of language ability which was partialed out in analyses.

The present study consisted of children completing the above tasks over a period of two forty-five minute sessions, while teachers completed two rating scales on their own time and returned them to the examiner. For the elementary school group, testing took place during school hours in a small conference room in the school library to allow for maximum privacy. Two under-graduate and one graduate student majoring in Psychology were trained in task administration and along with the author, conducted all testing at the school. Whenever possible each student administered a particular measure to allow for greater consistency. Students were expected to give their measure(s) to at least four pilot subjects before testing children for the study. For the Clarksburg clinic group, children were tested in a private office by the same 
examiner. The Erie clinic group was tested by trained undergraduate psychology students.

\section{Chapter 3: Results}

Following specific hypotheses outlined in the introduction, several different sets of analyses were conducted. First, descriptive information about the independent (Age, Conners' Subscales, TAPS-R, TACL-R) and dependent variables (Bandaid, Chocolate, Emotion Labels, Harter, SKI, Thought Bubbles) was obtained. Second, relations among variables were explored through zero-order correlations. Third, one-way ANOVA's were conducted to determine differences between the ADHD and non-ADHD groups on all variables. Finally, regression analyses were performed to determine the impact of auditory processing on theory of mind and social skills. Additional t-tests were also conducted which yielded no patterns for gender differences. Males and females did not differ significantly on the four independent variables: attention (mean $=50$ and 52 respectively), hyperactivity (mean $=52$ and 56), TACL-R $($ mean = 39 and 52) and TAPS-R (mean = 68 and 74) or the five dependent measures: Bandaid $($ mean = 3.67 and 3.73), Thought Bubbles (mean $=10.1$ and 10.4), Harter (mean = 22.3 and 22.7), SKI $($ mean $=17.7$ and 17.9) and Emotion labels (mean = 7.1 and 7.1). Therefore, all future analyses were collapsed across gender.

\section{Descriptive Analyses}

Table 1 shows the mean, standard deviation, and range for each of the variables in the present study. These data were examined for their distributions and for any univariate outliers. All variables met acceptable criteria for inclusion in further analyses except for the Chocolate task. The distribution of scores on this task was highly skewed in a positive direction due to the fact that all but two children reached ceiling levels, therefore it was dropped from further analysis. As expected, scores on the Bandaid task also approached ceiling levels, however, there was a significant difference between the performance of children with and without ADHD on this task, indicating a need for further analyses.

\section{$\underline{\text { Relatedness and Difficulty of Theory of Mind Tasks }}$}

In order to examine the relation between the two remaining theory of mind tasks, zero order correlations were conducted for the two subject groups separately and as a whole. The two theory of mind measures were found to be positively and significantly correlated at the $\underline{p}<.01$ level for the group as a whole $(\underline{r}=.41)$. However, when data for the ADHD and non-ADHD 
groups were analyzed separately, the two measures were significantly correlated for the ADHD group $(\underline{\mathrm{r}}=.48, \underline{\mathrm{p}}<.01)$, but not the non-ADHD group $(\underline{\mathrm{r}}=.17, \underline{\mathrm{p}}=\mathrm{n} . \mathrm{s}$.$) . Due to this fact, each$ measure was analyzed separately with respect to its relation to the independent variables.

In order to determine the relative difficulty of the two theory of mind measures, scores on the Bandaid and Thought Bubble tasks were converted to percentage correct and then their degree of difficulty compared. T-tests revealed that children performed significantly better on the Bandaid task $($ mean $=.74)$ than the Thought Bubble task $($ mean $=.57)(\underline{t}=5.69, \underline{\mathrm{p}}<.001)$. This trend also held true when each of group of children was analyzed separately. Children with ADHD did better on the Bandaid task $($ mean $=.68)$ than the Thought Bubble task $($ mean $=.45)$ $(\underline{t}=7.01, \underline{p}<.000)$. Scores on the Bandaid task $($ mean $=.79)$ were higher than those on the Thought Bubbles task $($ mean $=.69)(\underline{t}=2.29, \underline{p}<.029)$ for children without the disorder as well.

\section{$\underline{\text { Comparisons of ADHD and Non-ADHD Children }}$}

A series of one-way Analysis of Variance were conducted in order to look for differences between the two subject groups on all measures. Table 1 shows the means and significant $\mathrm{F}$ statistics (significance levels were determined using the Bonferoni correction for multiple analyses) for all variables. First, in relation to the theory of mind tasks, children diagnosed with ADHD did less well on both the Bandaid and Thought Bubbles tasks than did their non-ADHD peers. These same children also demonstrated less social competence as measured by the Social Knowledge Interview and teachers reported that children with ADHD were less socially appropriate than those without the disorder. However, the two groups did not differ significantly on the Emotion Labels task indicating some ability on the part of the ADHD children to accurately read visual cues. The two groups also differed on independent measures. As expected, children with ADHD were more inattentive and hyperactive. They were also less verbal and had more difficulty processing auditory stimuli than did their normal peers.

\section{$\underline{\text { Relations between Theory of Mind and Social Skills }}$}

In order to determine the relationship between theory of mind measures and social skills, partial correlations controlling for age and language ability (TACL-R percentile rankings) were conducted (Table 2). For the group as a whole, Emotion Labels were positively correlated with Thought Bubbles $(\underline{r}=.26, \underline{p}<.05)$ and ratings on the Harter were positively correlated with the two theory of mind measures $(\underline{r}=.33$ for both) at the $\underline{p}<.01$ level. For the ADHD group, the 
only significant correlation was between scores on the Harter and those on the Bandaid task $(\underline{r}=$ $.51, \mathrm{p}<.01)$. The non-ADHD group reported a negative correlation between the SKI and Thought Bubbles $(\underline{\mathrm{r}}=-.30, \underline{\mathrm{p}}<.05)$.

\section{Correlations between Theory of Mind, Social Skills, and Independent Variables}

For the next step in analysis, zero-order correlations were calculated between the independent variables (Age, Attention, Hyperactivity, TACL-R, and TAPS-R) and dependent variables (Bandaid, Thought Bubbles, SKI, Harter, Emotion Labels) for all subjects (Table 3). This analysis revealed that for the group as a whole, Age was positively and significantly correlated with performance on the Thought Bubbles task $(\underline{r}=.25)$. Attention and Hyperactivity standard scores on the Conners were negatively and significantly correlated with the Bandaid $(\underline{r}=$ -.34 and -.39 respectively), Thought Bubbles ( $\underline{r}=-.45$ for both), Harter $(\underline{r}=-.65$ and -.80$)$, and SKI ( $\underline{r}=.51$ and .61 respectively). While scores on the TACL-R and TAPS-R were positively and significantly correlated with scores on the Bandaid $(\underline{r}=.38$ and .44$)$, Thought Bubbles $(\underline{r}=$ .48 and .41$)$, Harter ( $\underline{r}=.41$ and .45$)$, and the SKI ( $\underline{r}=-.34$ and -.44$)$.

Identical analyses were then performed for the ADHD and non-ADHD groups separately. This revealed that Age was positively and significantly correlated with Thought Bubbles for the $\operatorname{ADHD}(\underline{\mathrm{r}}=.37)$ and non-ADHD group $(\underline{\mathrm{r}}=.38)$. The Hyperactivity standard score was negatively and significantly correlated with Thought Bubbles $(\underline{\mathrm{r}}=-.30)$, Harter $(\underline{\mathrm{r}}=-.55)$ and the SKI $(\underline{r}=.48)$ for children in the ADHD group. It was negatively and significantly correlated with scores on the Harter $(\underline{r}=-.64)$ for non-ADHD children. The TACL-R percentile ranking was positively and significantly correlated with scores on the Thought Bubbles $(\underline{r}=.40)$ for the nonADHD children, but was not significantly correlated with any dependent measures for the ADHD group. Scores on the TAPS-R were positively and significantly correlated with the Bandaid task $(\underline{r}=.43)$ and SKI $(\underline{r}=-.38)$ for the ADHD group only. The Attention Subscale of the Conners and the Emotion Labels task were not significantly correlated with any other variables for either group.

\section{$\underline{\text { Regression Analyses }}$}

Because the theory of mind tasks and social skills measures were significantly correlated with several intercorrelated independent variables, they were included in a series of regression analyses in order to examine which variables accounted for the most variance in children's 
performance. Five single-step multiple regressions including Age, Attention, Hyperactivity, TACL-R, and TAPS-R scores were conducted for the ADHD and non-ADHD groups separately, as well as for the group as a whole.

Tables 4 and 5 show the results of the multiple regressions for the ADHD and nonADHD groups respectively. For the Bandaid task, only scores on the TAPS-R accounted for a significant amount of unique variance in children with ADHD. The five variables together accounted for 28 percent of variance in performance, $F(5,25)=1.97, \underline{p}=n$.s. In children without ADHD, these variables only accounted for 8 percent of the variance in performance on the Bandaid task, $F(5,26)=.444, \mathrm{p}=$ n.s. and none of the betas for the predictors were significant.

Two of the five independent variables accounted for a significant amount of unique variance in children with ADHD for the Thought Bubbles task. Overall, these variables accounted for 41 percent of the variance, $F(5,25)=3.47, \underline{p}<.01$. For the non-ADHD children, betas for age and TACL-R scores were found to be significant, and together with the Attention, Hyperactivity, and TAPS-R scores accounted for 43 percent of the variance in performance, $F(5,26)=3.85, \mathrm{p}<.01$.

For the Social Knowledge Interview, only betas for the TAPS-R and Hyperactivity Subscale were found to be significant for children with ADHD. The five variables together accounted for 39 percent of the variance, $F(5,25)=3.23, \underline{p}<.05$. None of the variables contributed any unique variance on this task in children without ADHD as they together accounted for only 4 percent of variance in performance, $F(5,26)=.241, \underline{p}=$ n.s.

On the Harter, only betas for the Hyperactivity Subscale of the Conners were significant in either group. For children with ADHD, the variables accounted for 37 percent of variance, $F(5,25)=2.88, \underline{\mathrm{p}}<.05$, and for children without the disorder the variables accounted for 47 percent of variance, $F(5,26)=4.53, \mathrm{p}<.01$.

None of the variables contributed uniquely to performance on the Emotion Labels task for either group. The five variables accounted for only 7 percent of variance in both groups, $F(5,25)$ $=.362, \mathrm{p}=$ n.s. for children with $\mathrm{ADHD}$ and $F(5,26)=.42, \mathrm{p}=$ n.s. without the disorder.

Table 6 shows the results of regressions computed for the entire set of subjects. When Age, TACL-R, TAPS-R, Attention, and Hyperactivity were entered into the regression for the entire group, only TAPS-R scores contributed uniquely to performance on the Bandaid task. The 
five variables accounted for 26 percent of the variance in performance, $F(5,57)=3.93, \underline{p}<.01$.

In terms of the other theory of mind measure, Age, TACL-R, and TAPS-R all contributed uniquely to Thought Bubble performance. Together with Attention and Hyperactivity variables, they accounted for 51 percent of the variance in performance, $F(5,57)=11.81, \underline{p}<.0001$.

For the Harter and SKI, the beta score on the Hyperactivity Subscale of the Conners was the only one which was significant and together with the other four variables accounted for 42 percent of the variance in performance on the Social Knowledge Interview, $F(5,57)=8.26$, $\mathrm{p}<$ .0001 and 68 percent of variance in performance on the Harter, $F(5,57)=23.73, \underline{p}<.0001$. None of the variables contributed a unique amount of variance to performance on the Emotion Labels task $F(5,57)=.436, \mathrm{p}=$ n.s.

\section{Chapter 4 Discussion}

The purpose of the present study was to investigate the relation between theory of mind understanding, social skills, and auditory processing in elementary school children with and without Attention Deficit Hyperactivity Disorder. Several significant findings emerged from the data. Of initial importance is the fact that children with and without ADHD differed significantly on all dependent and independent variables except for the Emotion Labels task. This finding suggests that children with ADHD are just as capable as those without the disorder to accurately perceive social stimuli that are presented visually, but are less able to integrate information that is presented auditorily. This finding is helpful for anyone attempting to design a more effective social skills intervention program as it provides guidance for the medium by which to present information. This finding also seems to indicate that the ability to accurately read and label facial expressions is a more pure social skill that differs from other forms of social cognition. This lends credence to the idea that children with ADHD are able to learn distinct social skills, but continue to have difficulty in their social interactions. The fact that the two groups differed significantly on all other measures further indicates that children with ADHD evidence multiple deficits in cognitive functioning, from accurately perceiving auditory cues to understanding the beliefs of others.

In addition to identifying differences in the cognitive abilities of children with and without ADHD, a second goal of the study was to investigate the developmental nature of theory of mind understanding, as well as the relatedness of false belief and recursive thinking measures. 
Results indicate that children performed at ceiling level on what was expected to be the easiest theory of mind task and that age was significantly correlated with performance on the more difficult recursive thinking task. These findings confirm the developmental progression of theory of mind understanding posited in the introduction as it was expected that older children would perform better on the more complex tasks. The fact that there was some variability in performance on the Bandaid task, particularly in the ADHD group, is quite interesting. Because this study used a somewhat older age range than is seen in more traditional theory of mind studies, this finding seems to indicate that these children are somewhat behind their peers in their social cognitive development.

There was also some support for a relation between theory of mind understanding and social competence. When age and language ability were controlled for, scores on the Harter were significantly correlated with both theory of mind measures for the group as a whole. This finding is consistent with past studies which found a relationship between teacher ratings of social competence and theory of mind (Watson, Nixon, Wilson, \& Capage, 1999). When the two groups were analyzed separately, a negative relationship was found between the appropriateness of children's solutions to social problems and the more difficult recursive thinking task in children without ADHD. This was an unexpected finding as lower scores on the SKI were indicative of inappropriate responses. The highest correlation for children with ADHD was between scores on the Harter and the Bandaid task and indicates that children who are rated as more socially competent have a more well-developed understanding of false belief. Given the lack of coherence in these findings, it is important to consider that the results may be due to the restricted range of the measures rather than indicative of their true relationship.

In terms of the relation between independent variables, theory of mind, and social skills, zeroorder correlations and regression analyses indicated an effect of auditory processing and stimulus control which at times superceded the effects of age and language ability. In general, it appears that auditory attention is a better predictor of theory of mind understanding, while hyperactivity predicts social competence. It seems that children who process auditory stimuli more effectively also have a better theory of mind understanding, offer more appropriate solutions to social problems, and are better able to reason about information that is presented auditorily. Results also confirm traditional views that children who evidence less self-control are also less socially 
competent. Additionally, these findings indicate that specific executive processes may be essential for successful understanding of different types of social cognition.

A final contribution of this study relates to the "teachability" of theory of mind. Recently, a few studies have attempted to teach theory of mind in young children, but have met with limited success. In them, researchers read stories and led discussions with children in an attempt to expose them to subjects related to "mind" understanding. The present findings indicate that in addition to presenting such information auditorily, one may want to present it in a more visual form in order to overcome the more primitive auditory processing abilities of these young children.

In light of the present findings, there are several directions that future research in this area could take. First, one of the limitations with this study has to do with the extensive interrelatedness of the independent variables. Due to this fact, it is necessary to find measures which are not related to auditory language and each other in order to better identify the key aspects of auditory processing above and beyond language ability which may impact theory of mind understanding and social competence. Measures which are not correlated with verbal aptitude and which are more visual in nature (e.g., WISC-III performance subscales; processing speed) should be considered, as should specific measures of nonverbal attention such as an auditory Continuous Performance Task.

There also needs to be some consideration of the stimuli and methodology used with the false belief and recursive thinking tasks. Currently there is not a set of standardized instruments which can be used to measure theory of mind understanding, particularly in older children. Because of this, it is uncertain whether or not characteristics of the stimuli might have had an impact on individuals' performance. Once again, because stimuli were presented auditorily, it is also difficult to tease apart children's pure understanding of theory of mind and the effects of auditory processing ability. It is important to further investigate this question in light of past studies which have found that children who demonstrate deficits in self-regulation frequently report difficulty attending to the speech of others, as in the case of lectures, conversations, or verbal directions (Hooks, Milich, \& Lorch, 1994; Phelan, 1993).

The present study also has some limitations in terms of the different populations used. Even though care was taken to match the ADHD and non-ADHD groups on variables such as 
age, gender, and severity of symptoms, significant differences (i.e., age) still existed between the school and clinic groups. The impact of these differences on the present findings is unclear, however. Another limitation may lie in the nature of the data collection. It is possible that characteristics of the examiners themselves may have influenced children's performance on certain tasks. For example, they might have responded more appropriately on the SKI in order to gain the examiner's approval.

A study such as this one is important not only for its empirical findings, but also for its possible implications for clinical populations. The present investigation found that children with a decreased capacity for processing auditory stimuli, particularly those diagnosed with ADHD, have a less well-developed theory of mind. This means that these children have a compromised ability to obtain complete and accurate information about the thoughts and behavior of others in their environment, often resulting in inappropriate social behavior (Cunningham \& Siegel, 1987; Landau \& Milich, 1988).

There are currently several behaviorally-based programs that teach children with selfcontrol problems the basic skills necessary to get along with others in their environment (Abikoff \& Gittleman, 1984; Barkley, 1998). Most of these programs report at least some short-term success in teaching children with acting out problems appropriate social skills (Barkley, 1991). However, when these children are faced with "real life" situations, especially those dealing with conflict, their ability to access these skills appears to decline (Abikoff, 1991; Barkley, 1990) and they revert to more immature behavior (e.g., hitting). It seems that children with disorders of self-regulation are capable of learning to attend to and respond appropriately to environmental cues in a sterile setting, but they have difficulty generalizing stimulus control to novel situations. This may be particularly true when attention disordered children are under increased amounts of stress or are presented with novel stimuli. However, even after taking stimulant medication or participating in social skills training, many of these children continue to have difficulty in their relationships with others. One reason for this may be that the core of their social deficits is not acting out behavior, but the way they see the world around them. The present findings indicate that deficits in processing environmental stimuli appear to result in an inability to access information critical to the development of a concept of mind. In light of this information, social skills training programs should begin to target improvement of social cognitive skills and theory 
of mind understanding that appear to be critical for successfully interacting with others.

In conclusion, the present study is holds much importance for the field of counseling psychology. First, as previously mentioned, one of the limitations of the study is that many of the theory of mind and social skills measures are not yet standardized. Because of their background in assessment, counseling psychologists could be quite instrumental in developing a set of standardized protocols for future research. They would also have the expertise to train researchers in administration and scoring of these measures and offer ideas for ways in which they may be used in future research. Secondly, counseling psychologists could also provide a link between researchers and the general public by getting information such as this into schools. In their capacity as consultants and school counselors, counseling psychologist are afforded the unique opportunity to interact with students, teachers, and parents on a daily basis. This would allow them to disseminate new research findings to individuals who could put them to use with children. For example, counseling psychologists could educate teachers and parents about the importance of pretend play in young children and show them how to train children to play. 


\section{$\underline{\text { References }}$}

Abikoff, H. (1991). Cognitive training in ADHD children: Less to it than meets the eye. Journal of Learning Disabilities, 24(4), 205-209.

Abikoff, H., \& Gittelman, R. (1984). Does behavior therapy normalize the classroom behavior of hyperactive children? Archives of General Psychiatry, 41, 449-454.

Alessandri, S. M. (1992). Attention, play, and social behavior in ADHD preschoolers. Journal of Abnormal Child Psychology, 20(3), 289-302.

American Psychiatric Association. (1994). Diagnostic and statistical manual of mental disorders (4th. ed.). Washington, DC: Author.

Asher, S.R., \& Renshaw, P.D. (1981). Children without friends: social knowledge and social skill training. In The Development of Children's Friendships, ed. S.R. Asher \& J. Gottman, pp. 273-296. New York: Cambridge University Press.

Astington, J. W. (1993). The child's discovery of the mind. Cambridge, MA: Harvard University Press.

Astington, J.W. (1991). Intention in the child's theory of mind. In D. Frye \& C. Moore (Eds.), Children's Theories of Mind: Mental States and Social Understanding (pp. 157-172). Hillsdale, NJ: Lawrence Erlbaum Associates, Inc.

Astington, J. W., \& Gopnik. A. (1988). Knowing you've changed your mind: Children's understanding of representational change. In J. W. Astington, P.L. Harris, \& D. R. Olson (Eds.), Developing Theories of Mind. Cambridge: Cambridge University Press.

Astington, J.W., \& Jenkins, J. M. (1995). Theory of mind development and social understanding. Cognition and Emotion, $\underline{9}$, 151-165.

Barkley, R. (1998). Attention deficit hyperactivity disorder: A handbook for diagnosis and treatment. (2nd. ed.) New York: Guilford.

Barkley, R. (1996a). Critical issues in research on attention. In G.R. Lyon \& N.A. Krasnegor (Eds.), Attention, Memory, and Executive Function. (pp.45-56). Baltimore, MD: P.H. Brookes Publishing Co.

Barkley, R. (1996b). Linkages between attention and executive function. In G.R. Lyon \& N.A. Krasnegor (Eds.), Attention, Memory, and Executive Function. (pp.307-326). Baltimore, MD: P.H. Brookes Publishing Co. 
Barkley, R. (1991). The problem of stimulus control and rule-governed behavior in children with Attention Deficit Disorder with Hyperactivity. In J. Swanson \& L. Bloomingdale (Eds.)., Attention deficit disorders (vol. 4). New York: Pergamon Press.

Barkley, R. (1989). Attention deficit-hyperactivity disorder. In E. Mash \& R. Barkley (Eds.), Treatment of Childhood Disorders (pp. 39-72). New York: Guilford.

Barkley, R., Fischer, M., Newby, R., \& Breen, M. (1988). Development of a multimethod clinical protocol for assessing stimulant drug responses in ADHD children. Journal of Clinical Child Psychology, 17, 14-24.

Barkley, R. A., Grodzinsky, G., \& DuPaul, G. (1992). Frontal lobe functions in attention deficit disorder with and without hyperactivity: A review and research repot. Abnormal Child Psychology, 20, 163-188.

Barkley, R., McMurray, M., Edelbrock, C., \& Robbins, K. (1989). The response of aggressive and non-aggressive ADHD children to two doses of methylphenidate. Journal of the American Academy of Child and Adolescent psychiatry, 28, 873-881.

Baron-Cohen, S., Leslie, A. M., \& Frith, U. (1985). Does the autistic child have a "theory of mind"? Cognition, 21, 37-46.

Bartsch, K., \& Wellman, H. (1989). Young children's attribution of action to beliefs and desires. Child Development, $\underline{60}, 946-964$.

Berk, L. E., \& Potts, M. K. (1991). Development and functional significance of private speech among attention-deficit hyperactivity disordered and normal boys. Journal of Abnormal Child Development, 19(3), 357-376.

Brooks, R. B. (1994). Children at risk: Fostering resilience and hope. American Journal of Orthopsychiatry, 64(4). 545-553.

Brown, R. T., \& Borden, K. A. (1986). Hyperactivity at adolescence: Some misconceptions and new directions. Journal of Clinical Child Psychology, 15, 194-209.

Buhrmester, D., Whalen, C., Henker, B., MacDonald, V., \& Hinshaw, S. (1992). Prosocial behavior in hyperactive boys: Effects of stimulant medication and comparison with normal boys. Journal of Abnormal Child Psychology, 20(1), 103-120. 
Campbell, S. B. (1990). The socialization and social development of hyperactive children. In M. Lewis \& D. M. Miller (Eds.), Handbook of Developmental Psychopathology (pp. 77-92). New York: Plenum.

Campbell, S. B., \& Werry, J. S. (1986). Attention deficit disorder (hyperactivity). In H. C. Quay \& J. S. Werry (Eds.), Psychological Disorders of Childhood (3rd. ed., pp., 111-155). New York: Wiley.

Capage, L., \& Watson, A. (1999). Individual differences in theory of mind, aggressive behavior, and social skills in young children. Early Education and Development. Manuscript under review.

Carrow-Woolfolk, A. (1985). The Test for Auditory Comprehension of LanguageRevised. Riverside Publishing.

Castellanos, F. X., Giedd, J. N., Eckburg, P., Marsh, W. L., Vaituzis, C., Kaysen, D., Hamburger, S. D., \& Rapoport, J. L. (1994). Quantitative morphology of the caudate nucleus in attention deficit hyperactivity disorder. American Journal of Psychiatry, 151, 1791-1796.

Chandler, M.J. (1977). Social cognition: A selective review of current research. In W.F. Overton \& J.M. Gallagher (Eds.), Knowledge and Development. New York: Plenum.

Chandler, M., Fritz, A.S., \& Hala, S. (1989). Small-scale deceit: Deception as a marker of two-, three-, and four-year-olds' early theories of mind. Child Development, $\underline{60}, 1263-1277$.

Clark, M., Cheyne, J., Cunningham, C., \& Siegel, L. (1988). Dyadic peer interaction and task orientation in attention-deficit-disordered children. Journal of Abnormal Child Psychology, $\underline{16}, 1-15$.

Conners, C. K. (1997). Conners' Rating Scales-Revised (CRS-R) Technical Manual. North Tonawanda, New York: Multi-Health Systems Inc.

Conners, C. K. (1973). Rating scales for use in drug studies with children. Psychopharmacology Bulletin, Special issue (Pharmacotherapy of children), 24-84.

Conners, C. (1966). The effects of dexedrine on rapid discrimination and normal control of hyperkinetic children under mild stress. Journal of Nervous and Mental Diseases, 142,420 433. 
Cunningham, C., \& Siegel, L. (1987). Peer interactions of normal and attention-deficit disordered boys during free-play, cooperative task, and simulated classroom situations. Journal of Abnormal Child Psychology, 15, 247-268.

Dodge, K. (1993). Social-cognitive mechanisms in the development of conduct disorder and depression. Annual Review in Psychology, 44, 559-584.

Dodge, K. (1989). Coordinating responses to aversive stimuli: Introduction to a special section on the development of emotion regulation. Developmental Psychology, 25, 339-342.

Dodge, K. (1986). A social information processing model of social competence in children. In M. Perlmutter (Ed.), Minnesota symposia on child psychology (Vol. 18, pp. 75-127). Hillsdale, NJ: Lawrence Erlbaum.

Dodge, K. (1980). Social cognition and children's aggressive behavior. Child Development, $\underline{51}, 162-170$.

Dodge, K. \& Frame, C.L. (1982). Social cognitive biases and deficits in aggressive boys.

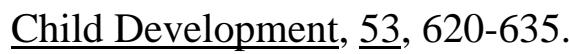

Eisenberg, N., Fabes, R. A., Bernzweig, J., Karbon, M., Poulin, R., \& Hanish, L. (1993). The relations of emotionality and regulation to preschoolers' social skills and sociometric status. Child Development, , 62, 1418-1438.

Eliot, J., Lovell, K., Dayton, C., \& McGrady, B. (1979). A further investigation of children's understanding of recursive thinking. Journal of Experimental Child Psychology, 28, 149-157.

Erhardt, D., \& Hinshaw, S. P. (1994). Initial sociometric impressions of attention-deficit hyperactivity disorder and comparison boys: Predictions from social behaviors and from nonbehavioral variables. Journal of Consulting and Clinical Psychology, 62(4), 833-842.

Flicek, M. (1992). Social status of boys with both academic problems and attentiondeficit hyperactivity disorder. Journal of Abnormal Child Psychology, 20(4), 353-366.

Frederick, B. P., \& Olmi, D. J. (1994). Children with attention deficit/hyperactivity disorder: A review of the literature on social skills deficits. Psychology in the Schools, $\underline{\text { 31(4), }}$ 288-296.

Gardner, M. F. (1997). Test of Auditory-Perceptual Skills, Revised. Burlingame, CA: Psychological and Educational Publications, Inc. 
Gopnik, A. (1993). How we know our minds: The illusion of first-person knowledge of intentionality. Behavioral and Brain Sciences, $16,1-14$.

Gopnik, A., \& Slaughter, V. (1991). Young children's understanding of changes in their mental states. Child Development, $\underline{62}, 98-110$.

Gordon, M., Thomason, D., Cooper, S., \& Ivers, C. (1991). Nonmedical treatment of ADHD/Hyperactivity: The attention training system. Journal of School Psychology, 29, 151159.

Gresham, F., \& Elliott, S. (1987). The relationship between adaptive behavior and social skills: Issues of definition and assessment. The Journal of Special Education, 21, 167-181.

Guevremont, D. (1990). Social skills and peer relationship training. In R. A. Barkley, (ed.), Attention deficit hyperactivity disorder: A handbook for diagnosis and treatment (pp. 540572). New York: Guilford.

Guevremont, D., \& Dumas, M. (1994). Peer relationship problems and disruptive behavior disorders. Journal of emotional and Behavioral Disorders, 2(3), 164-172.

Hallowell, E., \& Ratey, J. (1993). Driven to distraction: Recognizing and coping with attention deficit disorder from childhood through adulthood. New York: Simon \& Schuster.

Harter, S. (1979). Perceived Competence Scale for Children: Manual. Denver, CO: University of Denver.

Hartsough, C., \& Lambert, N. (1985). Medical factors in hyperactive and normal children: Prenatal, developmental, and health history findings. American Journal of Orthopsychiatry, 55, 190-210.

Hinshaw, S. P., Buhrmester, D., \& Heller, T. (1989). Anger control in response to verbal provocation: Effects of stimulant medication for boys with ADHD. Journal of Abnormal child Psychology, 17(4), 393-407.

Hinshaw, S., \& Melnick, S. (1992). Self-management therapies and attention-deficit hyperactivity disorder. Behavior Modification, 16(2), 253-273.

Hooks, K., Milich, R., \& Lorch, E.P. (1994). Sustained and selective attention in boys with attention deficit hyperactivity disorder. Journal of Clinical Child Psychology, 23, 69-77. 
Hoza, B., Pelham, W. E., Milich, R., Pillow, D., et-al. (1993). The self-perceptions and attributions of attention deficit hyperactivity disordered and nonreferred boys. Journal of Abnormal Child Psychology, 21(3), 271-286.

Hubbard, J. A., \& Newcomb, A. F. (1991). Initial dyadic peer interaction of attention deficit-hyperactivity disorder and normal boys. Journal of Abnormal Child Psychology, 19(2), 179-195.

Ialongo, N., Lopez, M., Horn, W., Pascoe, J., \& Greenberg, G. (1994). Effects of psychostimulant medication on self-perceptions of competence, control, and mood in children with attention deficit hyperactivity disorder. Journal of Clinical Child Psychology, 23(2), 161173.

Joffe, R. D., Dobson, K. S., Fine, S., Marriage, K., \& Haley, G. (1990). Social problem solving in depressed, conduct-disordered, and normal adolescents. Journal of Abnormal Child Psychology, 18(5), 565-575.

Kauffman, J. M. (1993). Characteristics of emotional and behavioral disorders of children and youth (5th ed.). New York: Merrill.

Kelly, J., \& Ramundo, P. (1992). You mean I'm not lazy, stupid, or crazy? Cincinnati: Tyrell \& Jerem.

Klein, R. G., \& Mannuzza, S. (1991). Long-term outcome of hyperactive children: A review. Journal of the American Academy of Child and Adolescent Psychiatry, $\underline{30}$, 383-387.

Kolko, D., Loar, L., \& Sturnick, D. (1990). Inpatient social-cognitive skills training groups with conduct disordered and attention deficit disordered children. Journal of Child Psychology and Psychiatry, 31(5), 737-748.

Lalonde, C., E., \& Chandler, M. J. (1995). False belief understanding goes to school: On the social-emotional consequences on coming early or late to a first theory of mind. Cognition and Emotion, 9, 167-186.

Landau, S., \& Milich, R. (1988). Social communication patterns of attention-deficitdisordered boys. Journal of Abnormal Child Psychology, 16, 69-81.

Landau, S., \& Moore, L. A. (1991). Social skill deficits in children with attention deficit hyperactivity disorder. School Psychology Review, 20(2), 235-251. 
Lewis, C., \& Osborne, A. (1990). Three-year-olds' problems with false belief: Conceptual deficit or linguistic artifact? Child Development, 61, 1514-1519.

Linn, R., \& Hodge, G. (1982). Locus of control in childhood hyperactivity. Journal of Consulting and Clinical Psychology, 50, 592-593.

Milich, R., \& Dodge, K. (1984). Social information processing in child psychiatric populations. Journal of Abnormal Child Psychology, 12, 471-490.

Milich, R., \& Landau, S. (1982). Socialization and peer relations in hyperactive children. In K. D. Gadow \& I. Bialer (Eds.), Advances in learning and behavioral disabilities. Greenwich, CT: JAI Press.

Miller, P., Kessel, F., \& Flavell, J. (1970). Thinking about people thinking about people thinking- A study of social cognitive development. Child Development, 41, 613-623.

Murphy, D. A., Pelham, W. E., \& Lange, A. R. (1992). Aggression in boys with attention deficit-hyperactivity disorder: Methylphenidate effects on naturalistically observed aggression, response to provocation, and social information processing. Journal of Abnormal Child Psychology, 20(5), 451-466.

Nichols, P., \& Chen, T. (1981). Minimal brain dysfunction: A prospective study. Hillsdale, NJ: Erlbaum.

Oppenheimer, L. (1986). Development of recursive thinking: Procedural variations. International Journal of Behavioral Development, 9, 401-411.

Palfrey, J., Levine, M., Walker, D., \& Sullivan, M. (1985). The emergence of attention deficits in early childhood: A prospective study. Developmental and Behavioral Pediatrics, $\underline{6}$, 339-348.

Parker, J. G., \& Asher, S. R. (1987). Peer relations and later personal adjustment: Are low-accepted children at risk? Psychological Bulletin, 102, 357-389.

Pearson, D., Lane, D., \& Swanson, J. (1991). Auditory attention switching in hyperactive children. Journal of Abnormal Child Psychology, 19, 479-492.

Perner, J. (1991). Understanding the representational mind. Cambridge, MA: The MIT Press.

Perner, J., Ruffman, T., \& Leekam, S.R. (1994). Theory of mind is contagious: You catch it from your sibs. Child Development, $\underline{65}, 1228-1238$. 
Perner, J., \& Wimmer, H. (1985). "John thinks that Mary thinks that . . " Attribution of second-order beliefs by 5-10 year old children. Journal of Experimental Child Psychology, 39, 437-471.

Phelan, T. (1993) All about attention deficit disorder: Symptoms, diagnosis, and treatment. Glen Ellyn, IL: Child Management Inc.

Pope, A., Bierman, L., \& Mumma, G. (1989). Relations between hyperactive and aggressive behavior and per relations at three elementary grade levels. Journal of Abnormal Child Psychology, 17, 253-267.

Ross, D. M., \& Ross, S. A. (1982). Hyperactivity: Current issues, research, and theory (2nd. ed.). New York: Wiley.

Safer, D., \& Krager, J. (1988). A survey of medication treatment for hyperactive/inattentive students. Journal of the American Medical Association, 260, 2256-2258.

Schwiebert, V., Sealander, K., \& Tollerud, T. (1995). Attention-deficit hyperactivity disorder: An overview for school counselors. Elementary School Guidance \& Counseling, 29, 249-259.

Shatz, M., Wellman, H. M., \& Silber, S. (1983). The acquisition of mental verbs: A systematic investigation of the first reference to mental state. Cognition, $\underline{14}, 301-321$.

Shaywitz, S. E., \& Shaywitz, B. A. (1992). Attention deficit disorder comes of age: Toward the twenty-first century. Austin, TX: Pro-Ed.

Tannock, R., Purvis, K. L., \& Schachar, R. J. (1993). Narrative abilities in children with attention deficit hyperactivity disorder and normal peers. Journal of Abnormal child Psychology, $\underline{21(1)}, 103-117$.

Trites, R. L., Blouin, A. G., Ferguson, H., \& Lynch, G. W. (1981). The Conner's Teacher Rating Scale: An epidemiological inter-rater reliability and follow-up investigation. In K. Gadow \& J. Loney (eds.), Psychosocial aspects of drug treatment for hyperactivity. Boulder, CO: Westview Press.

Veith, D. (1980). Recursive thinking and the self-concepts of preadolescents. The Journal of Genetic Psychology, 137, 233-246.

Watson, A., Nixon, C., Wilson, A., \& Capage, L. (1999). Social interaction skills and theory of mind in young children. Developmental Psychology, 35, 386-391. 
Weiss, G., \& Hechtman, L. (1993). Hyperactive children grown up: ADHD in children, adolescents, and adults (2nd ed.). New York: Guilford.

Wenar, C. (1994). Developmental psychopathology: From infancy through adolescence (3rd. ed.). New York: McGraw-Hill.

Whalen, C. K. (1989). Attention deficit and hyperactivity disorders. In T. H. Ollendick \& M. Hersen (Eds.), Handbook of Child Psychopathology (pp. 131-169). New York: Plenum.

Whalen, C., \& Henker, B. (1985). The social worlds of hyperactive children. Clinical Psychology Review, 5, 1-32.

Whalen, C., Henker, B., Collins, B., McAuliffe, S., \& Vaux, A. (1979). Peer interaction in structured communication task: Comparisons of normal and hyperactive boys and of methylphenidate and placebo effects. Child Development, $\underline{50}, 388-401$.

Wheeler, J., \& Carlson, C. L. (1994). The social functioning of children with ADD with hyperactivity and Add without hyperactivity: A comparison of their peer relations and social deficits. Journal of Emotional and Behavioral Disorders, 2, 2-12.

Wilson, A. G., Watson, A. C., \& Yura, M. T. (1998). Theory of mind development and self-regulation in young school children. (manuscript in preparation).

Wimmer, H., \& Perner, J. (1983). Beliefs about beliefs: Representation and constraining function of wrong beliefs in young children's understanding of deception. Cognition, 13, 103-128. 
Table 1

Mean, Standard Deviation, and Range for All Variables

\begin{tabular}{|c|c|c|c|c|c|c|c|}
\hline & \multicolumn{3}{|c|}{ ADHD } & \multicolumn{3}{|c|}{ NON-ADHD } & \multirow[t]{2}{*}{$\underline{F}$} \\
\hline & Mean & SD & Range & Mean & $\mathrm{SD}$ & Range & \\
\hline AGE & 99.32 & 15.09 & $66-119$ & 95.47 & 11.91 & $66-119$ & $\underline{F}(1,61)=1.27$ \\
\hline ATTENTION & 60.06 & 9.35 & $42-80$ & 42.81 & 3.32 & $41-55$ & $\underline{F}(1,61)=96.56^{* *}$ \\
\hline BANDAID & 3.42 & .76 & $2-5$ & 3.97 & .78 & $3-5$ & $\underline{F}(1,61)=7.94 *$ \\
\hline CHOCOLATE & 1.94 & .36 & $0-2$ & 1.97 & .18 & $1-2$ & $\underline{F}(1,61)=.220$ \\
\hline EMOTION LABELS & 6.74 & 1.75 & $1-9$ & 7.37 & 1.74 & $1-10$ & $\underline{F}(1,61)=2.08$ \\
\hline HARTER & 18.45 & 4.97 & $10-28$ & 26.34 & 1.96 & $21-28$ & $\underline{\mathrm{F}}(1,61)=69.49 * *$ \\
\hline HYPERACTIVITY & 63.39 & 10.95 & $43-84$ & 43.97 & 4.69 & $39-54$ & $\underline{F}(1,61)=84.62 * *$ \\
\hline SKI & 16.35 & 3.54 & $8-20$ & 1916 & 1.27 & $14-20$ & $\underline{F}(1,61)=17.72 * *$ \\
\hline TACL-R & 28.16 & 27.13 & $1-87$ & 61.78 & 28.13 & $6-99$ & $\underline{F}(1,61)=23.29 * *$ \\
\hline TAPS-R & 62.45 & 17.17 & $36-98$ & 79.19 & 13.16 & $52-101$ & $\underline{F}(1,61)=18.92 * *$ \\
\hline THOUGHT BUBBLES & 8.10 & 3.63 & $1-17$ & 12.34 & 4.40 & $2-18$ & $\underline{F}(1,61)=17.43^{* *}$ \\
\hline
\end{tabular}

$* \mathrm{p}<.01 . * * \mathrm{p}<.001$. 
Table 2

$\underline{\text { Relations between Theory of Mind and Social Skills }}$

\begin{tabular}{|c|c|c|c|c|c|c|}
\hline & \multicolumn{3}{|c|}{ BANDAID } & \multicolumn{3}{|c|}{ THOUGHT BUBBLES } \\
\hline & ADHD & NON & ВОТН & ADHD & $\mathrm{NON}$ & ВОТН \\
\hline EMOTION LABELS & .05 & .01 & .05 & .17 & .29 & $.26^{* *}$ \\
\hline HARTER & $.51 * *$ & -.18 & $.33 * *$ & .24 & .08 & $.33 * *$ \\
\hline $\begin{array}{l}\text { SOCIAL KNOWLEDGE } \\
\text { INTERVIEW }\end{array}$ & .16 & -.04 & .15 & .11 & $-.30 *$ & .09 \\
\hline
\end{tabular}

$* \underline{p}<.05 . * * \underline{p}<.01$ 
Table 3

Correlations between Theory of Mind, Social Skills, and Independent Variables

\begin{tabular}{|c|c|c|c|c|c|c|c|c|c|c|c|c|c|c|c|}
\hline & \multicolumn{3}{|c|}{ BANDAID } & \multicolumn{3}{|c|}{$\begin{array}{l}\text { THOUGHT } \\
\text { BUBBLES }\end{array}$} & \multicolumn{3}{|c|}{ SKI } & \multicolumn{3}{|c|}{ HARTER } & \multicolumn{3}{|c|}{$\begin{array}{l}\text { EMOTION } \\
\text { LABELS }\end{array}$} \\
\hline & ADHD & NON & ВOTH & ADHD & NON & ВOTH & ADHD & NON & ВОTH & ADHD & NON & вотн & ADHD & NON & ВOTH \\
\hline AGE & -.03 & -.05 & -.09 & $.37 * *$ & $.38 * *$ & $.25^{*}$ & .01 & .18 & -.03 & .11 & $.30 *$ & -.00 & .19 & -.00 & .08 \\
\hline ATTENTION & -.15 & -.11 & $-.34 * *$ & -.13 & -.27 & $-.45^{* *}$ & -.27 & -.08 & $-.51 * *$ & -.18 & -.28 & $-.65 * *$ & .05 & .07 & -.11 \\
\hline HYPERACTIVITY & -.25 & -.03 & $-.36 * *$ & $-.30 *$ & -.04 & $-.46 * *$ & $-.48 * *$ & -.10 & $-.61 * *$ & $-.55 * *$ & $-.64 * *$ & $-.81 * *$ & -.10 & .25 & -.13 \\
\hline TACL-R & .26 & .24 & $.38 * *$ & .20 & $.40 * *$ & $.48 * *$ & .23 & -.09 & $.34 * *$ & .02 & .11 & $.41 * *$ & -.09 & .11 & .11 \\
\hline TAPS-R & $.43^{* *}$ & .23 & $.44 * *$ & .24 & .25 & $.41 * *$ & $.38^{*}$ & -.02 & $.44 * *$ & .18 & .12 & $.45^{* *}$ & .05 & .02 & .12 \\
\hline
\end{tabular}

$* \mathrm{p}<.05 . * * \mathrm{p}<.01$ 
Table 4

$\underline{\text { Regression Analyses Predicting Theory of Mind and Social Competence in Children with ADHD }}$

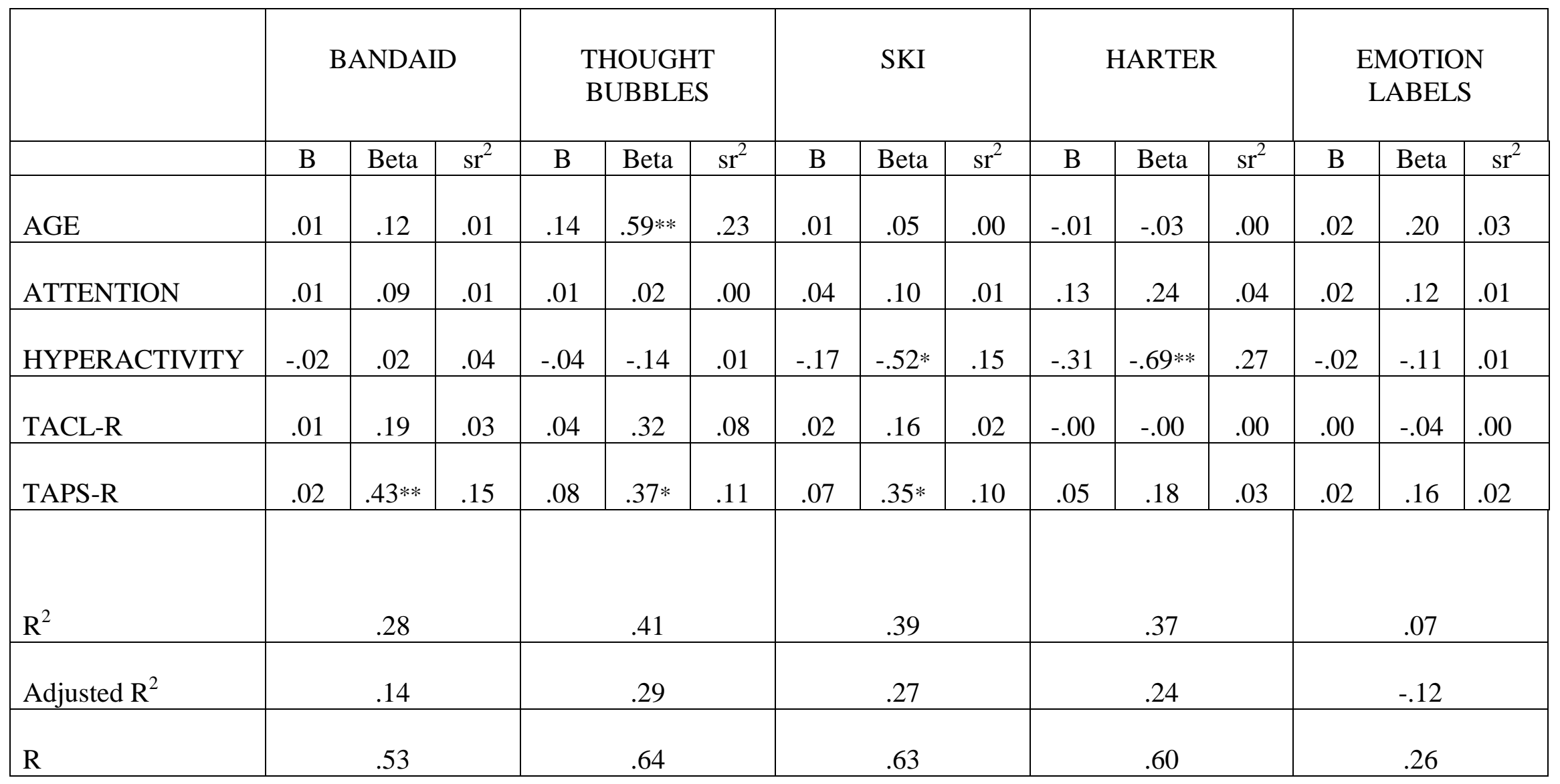

$* \mathrm{p}<.05 * * \mathrm{p}<.01$ 
Table 5

$\underline{\text { Regression Analyses Predicting Theory of Mind and Social Competence in Children without ADHD }}$

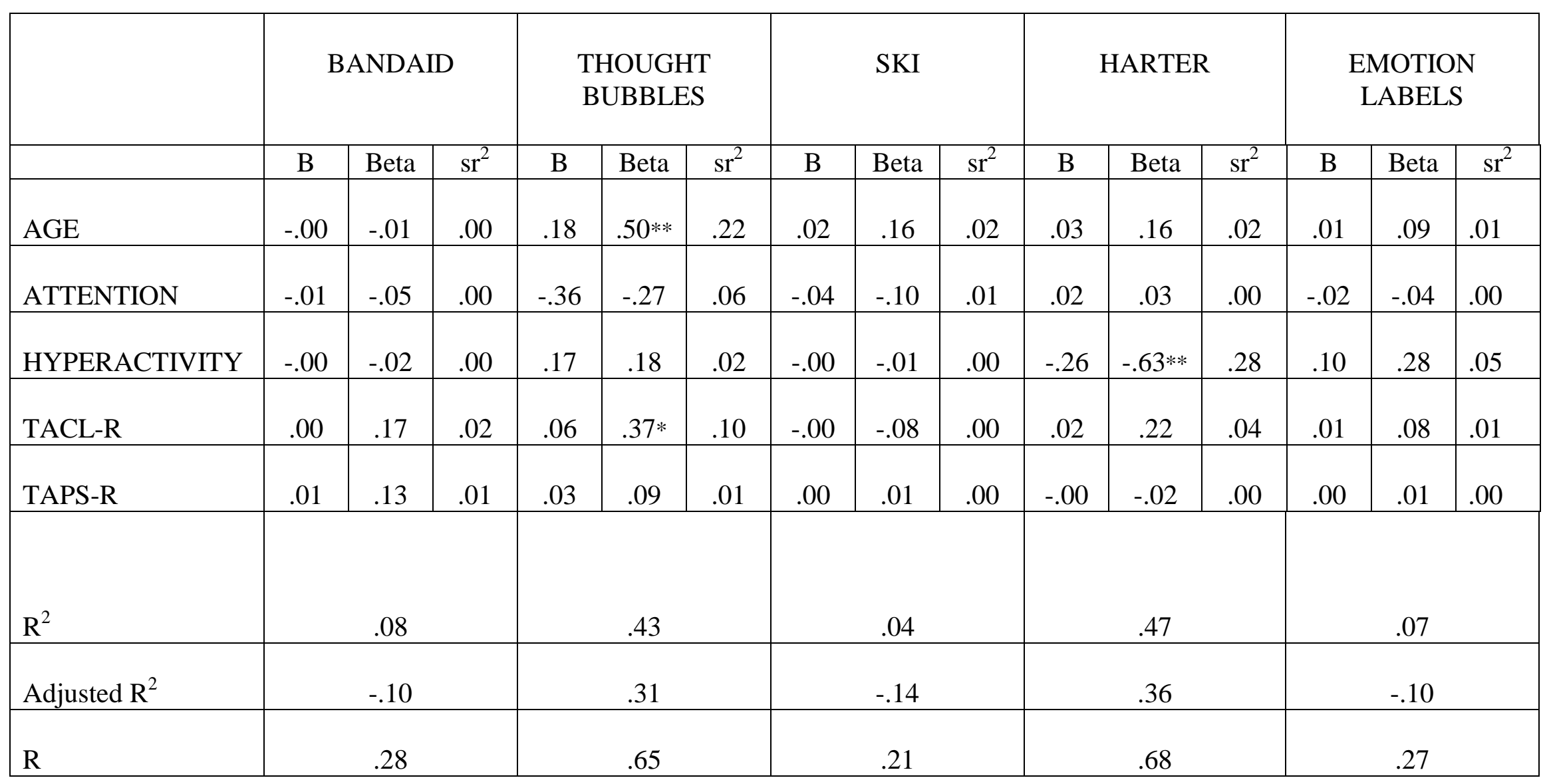

$* \mathrm{p}<.05 \quad * * \mathrm{p}<.01$ 
Table 6

$\underline{\text { Regression Analyses Predicting Theory of Mind and Social Competence in Both Groups of Children }}$

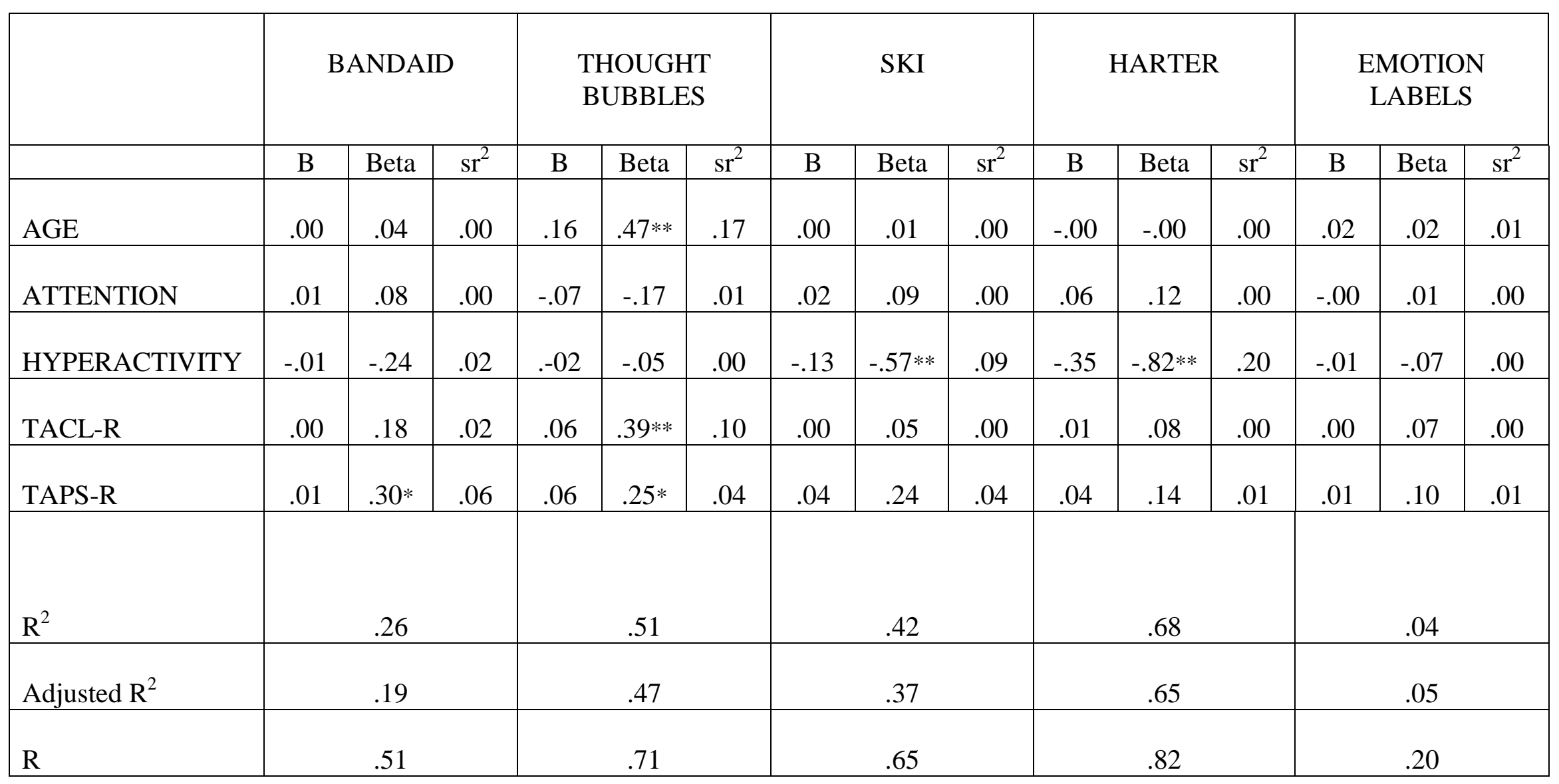

$* \mathrm{p}<.05 * *$ p $<.01$ 


\section{Amy Wilson Strange \\ 12386 Risman Dr. Apt. 204 \\ Plymouth, MI 48170 \\ (734) 354-1896 (h) \\ jnastrange@mail.wwnet.net}

\section{EDUCATION}

Ph.D. in Counseling Psychology, West Virginia University, August 1999, GPA 4.0.

-- Comprehensive exams passed September 1997

-- Dissertation defended July 1999, "Social Competence and Theory of Mind

Development in Elementary School Children with Attention Deficits"

-- Internship completed at Hawthorn Center in Northville, MI, August 1999

Ph.D. in Developmental Psychology, West Virginia University, May 1998, GPA 3.98.

-- Comprehensive exams passed September 1995

-- Dissertation defended, April 1998, "Theory of Mind Development and Self-Regulation in Young School Children"

M.A. in Elementary School Counseling, West Virginia University, May 1993, GPA 4.0.

B.A. in Psychology, West Virginia University, May 1991, GPA 3.79.

-- Magna Cum Laude.

-- Honor's Thesis completed May 1991, “Children's Responses to Interadult Anger as a Function of Type of Resolution"

\section{CLINICAL EXPERIENCE}

\section{Counseling Psychology Doctoral Internship}

Hawthorn Center, Northville, MI

September 1998 to August 1999

Site supervisors: Joy Wolfe Ensor, Ph.D., L.P.; Georgia Michalopoulou, Ph.D., L.P.

Provided individual, family, and group therapy in a child/adolescent inpatient hospital and outpatient setting. Responsible for psychological and child custody evaluations. Co-lead Early Childhood Intervention group for preschool children and parents at an outpatient clinic. Conducted initial clinical evaluations and developed comprehensive treatment plans. Worked as part of a milieu team consisting of psychologists, psychiatrists, nurses, social workers, teachers, and child care professionals at the inpatient facility. Worked with children and adolescents ages 3 to 18 who were diagnosed with ADHD, ODD, depression, schizophrenia, conduct disorder, eating disorders, autism, borderline personality, and separation anxiety. 


\title{
Counseling Psychology Doctoral Practicum
}

\author{
Monongalia County School System, Morgantown, WV \\ January 1997 to June 1998 \\ Site supervisor: J. Michael Fike, M.A., L. P. C. \\ Academic supervisor: L. Sherilyn Cormier, Ph.D., L. P.
}

Provide individual and group therapy for children in grades K-6. Developed and currently implementing classroom guidance program focused on emotion understanding and tolerance. Provide family counseling and parent support for low-income, at-risk families. Perform academic and intellectual assessments. Provide consultation for teachers, counselors, and school administrators. Conduct parent education workshops and teacher inservice programs on managing childhood aggression. Extensive work with children demonstrating disruptive behavior problems, ADHD, school phobia, abuse issues, and learning disabilities. Receive weekly group and individual supervision.

\section{Counseling Psychology Doctoral Practicum}

\author{
United Hospital Summit Center, Clarksburg, WV \\ October 1997 through July 1998 \\ Site supervisor: Tom Bell, Ph.D., L. P. \\ Academic supervisor: L. Sherilyn Cormier, Ph.D., L. P.
}

Provide individual therapy for children diagnosed with Attention Deficit Hyperactivity Disorder or physical/sexual abuse histories. Training in psychological assessment and abuse intakes. Co-leading two support/education groups with Dr. Bell for parents of children diagnosed with ADHD or other disruptive behavior disorders. Receive weekly individual supervision.

\section{Developmental Psychology Doctoral Practicum}

Mountainview Elementary School, Morgantown, WV

August 1994 to May 1995

Site supervisor: J. Michael Fike, M.A., L. P. C.

Academic supervisor: Tracy L. Morris, Ph.D., L. P.

Provided classroom guidance for grades K-6, focusing on social skills and problem solving. Developmental guidance consisted of weekly class meetings and activities. Provided individual and group counseling. Developed and lead the following groups: children of alcoholics, divorce, social skills, ADHD support. Received weekly individual supervision. 


\section{Counseling Master's Internship}

Mountainview Elementary School, Morgantown, WV

January to June 1993

Site supervisors: J. Michael Fike, M.A., L. P. C.; Carolyn Grove, M.A.

Academic supervisors: David Srebalus, Ed.D., L. P.; Michael T. Yura, Ph.D., L. P.

Provided individual and group counseling to children in grades K-6. Consulted with teachers in developing behavior plans for classroom management. Conducted assessment screening for special education placements. Provided classroom guidance for grades 3-6. Worked with children demonstrating behavior disorders, anxiety, depression, learning disabilities, and abuse.

\section{Counseling Master's Practicum}

First and Second Ward Elementary Schools, Morgantown, WV

September to December 1992

Site supervisor: Carolyn Dean, M.A., L. P. C.

Academic supervisors: David Srebalus, Ed.D., L. P., Michael T. Yura, Ph.D., L. P.

Provided individual and group counseling to children in grades K-6. Conducted school orientation meetings for new students. Consulted with teachers in writing behavior plans for students demonstrating disruptive classroom behaviors.

\section{PROFESSIONAL EXPERIENCE}

\section{Graduate Assistantships}

Countywide Consultant with Monongalia County School System, Morgantown, WV August 1997 to June 1998

Supervisor: Janice Christopher, Ed.D., L. P.

Multifaceted position requiring assessment of children experiencing: serious academic underachievement, chronic absence from school, or multiple referrals for behavior problems. Provide school consultation, individual/family counseling, and development of behavior modification programs for students in grades K - 4 at eight elementary schools.

Counselor with Monongalia County School System, Morgantown, WV

August 1996 to June 1997

Supervisor: David Srebalus, Ed.D., L. P.

Position required working with at-risk elementary school children and their families. Developed family support program for low income housing complex. 
Morgantown Day School, Morgantown, WV

August 1993 to June 1994

Supervisor: Tracy L. Morris, Ph.D., L. P.

Responsible for developing and implementing a classroom management program and individual behavior modification plans for students in grades 2-6 at a private elementary school. Consulted with school personel and parents to develop a classroom guidance program which addressed developmental needs of the children.

\section{Tutor/counselor}

Student Support Services, West Virginia University

April 1994 to December 1995

Responsible for academic tutoring and individual counseling of first generation college students from rural communities. Advised students on class scheduling, major selection, and adjustment to college in addition to providing support in specific courses. Provided one-on-one contact as well as delivered seminars to small groups of students.

\section{Crisis Team Member}

Mountainview Elementary School, Morgantown, WV

May 1993 to June 1998

Received training in school wide crisis management. Available to provide counseling should a school or county emergency occur.

\section{Consultant}

Southern Middle School, Oakland, MD

September to December 1992

Supervisor: Michael T. Yura, Ph.D., L. P.

Provided individual and group counseling with at risk adolescents. Consulted with teachers to develop individual behavior plans as needed. Worked with adolescents who had significant abuse histories.

\section{Group Leader}

Human Sexuality (MDS 60), West Virginia University

August 1992 to May1993

Supervisor: Rev. Reba Thurmond

Provided leadership for a growth group of 15 college students enrolled in a human sexuality course. 


\section{SUPERVISORY ACTIVITIES}

\section{Pre-doctoral Practicum, Summer 1999}

Responsible for training a student completing a pre-doctoral practicum at an inpatient psychiatric hospital for children and adolescents. Responsible for overseeing therapeutic interventions and assessments, as well as instructing the student in ethical and theoretical principles of clinical psychology.

\section{Master's Assessment Practicum, Fall 1997}

Responsible for training and coordinating 25 Master's Counseling students in screening of elementary school children for special education placement. Utilized K-Bit, PIAT, SIT, Woodcock Johnson Test of Academic Achievement, Connor's, Child Behavior Checklist, and classroom observation. Taught students test administration/scoring procedures and report writing skills.

Master's Level Counseling Internship and Practicum, Fall 1997, August 1994May 1995.

Supervision of five students pursuing a Master's Degree in Elementary School Counseling. Supervision activities included individual and group supervision, review of audiotapes, co-therapy, and co-leadership of social skills groups.

Undergraduate Teaching Assistants, Spring 1994, Summer 1994, Spring 1995, Spring 1996, Spring 1997, Summer 1997

Supervised 7 students in learning teaching skills. Students graded papers, led activities, and presented lectures in undergraduate psychology courses.

\section{Graduate and Undergraduate Research Assistants, January 1994 - July 1998}

Supervisor of 4 graduate and 17 undergraduate psychology students who wrote literature reviews, collected data, coded data, and entered data in the computer for various research projects. Weekly meetings were also held each semester during which time research issues were discussed (i.e., subject recruitment) and skills such as technical writing, data analysis, and study development were taught.

\section{Mentor, High School Honor’s Student, September 1996 - May 1997}

Taught student research skills and aided her in developing her own Honor's Thesis on the topic of vocational interest in school children. 


\section{TEACHING EXPERIENCE}

\section{Graduate Teaching Assistant}

Gender Role Development (Psychology 170)

West Virginia University

Summer 1997, Spring 1997, Summer 1996, Spring 1996, Summer 1995

Responsible for development and instruction of course consisting of 35-64 students. Course focused on gender development and related issues.

Exceptional Children (Psychology 282)

West Virginia University

Spring 1996, Fall 1996

Supervisor: Cheryl B. McNeil, Ph.D., L. P.

Responsible for leading discussions/activities and proctoring exams. Also delivered lectures on childhood depression and communication disorders. Course focused on diagnosis and treatment of disorders of childhood and adolescence.

Introduction to Human Development (Psychology 141)

West Virginia University

August 1995 to May 1996

Supervisor: Anne W. O'Reilly, Ph.D.

Responsible for delivering lectures and exams to 130 students each semester. Course focused on human physical, cognitive, and social development.

Senior Seminar: Applying to graduate school (Psychology 190)

West Virginia University

Fall 1995

Team taught course with six other graduate students. Course aimed to prepare psychology students for graduate school.

Child Behavior Modification (Psychology 364)

West Virginia University

Fall 1995

Supervisor: Cheryl B. McNeil, Ph.D., L. P.

Responsible for conducting skill check-outs, leading class discussions, and proctoring exams. Course focused on clinical interventions with children demonstrating various diagnoses. 
Introductory Psychology (Psychology 1)

West Virginia University

August 1991 to May 1995

Supervisors: Kevin Larkin, Ph.D., L. P.; Tracy L. Morris, Ph.D., L. P.

Responsible for writing and delivering lectures and exams to 120 students each semester.

Guest Lecturer (West Virginia University)

Introduction to Social Psychology (Psychology 151)

"Aggression," "Obedience and Social Influence," "Love and Affiliation," "Social

Cognition"

Exceptional Children (Psychology 282)

"Learning Disabilities," "Speech and Language Problems," "Gifted and Talented,"

"Childhood Depression," "Hearing Impairment," "Communication Disorders," "Child Abuse and Neglect"

Child Behavior Modification (Psychology 364)

"Attention Deficit Hyperactivity Disorder," "Depression in Children and Adolescents,"

"Social Skills Training"

\section{WORK EXPERIENCE}

\section{Research Assistant}

Survey Associates (private survey firm)

May to August 1996

Supervisors: Tracy L. Morris, Ph.D., L. P.; Joseph Scotti, Ph.D., L. P.

Responsible for conducting clinical interviews and psychological assessments of individuals who have experienced a significant trauma (e.g., car accident) or disaster (e.g., chemical leak).

\section{Summer Program Director}

Morgantown Day School

Summer 1990-1995

Developed and administered a summer day care program for twenty-five children ages 6-12.

\section{Supervisor of Afterschool Program}

Morgantown Day School

January 1990-December 1992

Responsible for planning and supervising activities for fifteen children in an elementary school afterschool program. 


\section{Tutor}

West Virginia University

September 1988-May 1989

Tutored college freshmen in math, statistics, chemistry, biology, and psychology.

\section{PUBLICATIONS}

Wilson, A., Watson, A., \& Yura, M. "Theory of Mind Development and Self-Regulation in Young School Children." To be submitted to Child Development.

Wilson, A. (in preparation). The dilemma of confidentiality with young children: When is it "ok" to tell parents. To be submitted to $\underline{\text { School Counselor. }}$

Cummings, E. M., \& Wilson, A. G. (1999). Contexts of marital conflict and children's emotional security: Exploring the distinction between constructive and destructive conflict from the children's perspective. In M. Cox \& J. Brooks-Gunn (Eds.), Formation, functioning, and stability of families. Mahwah, NJ: Erlbaum.

O'Reilly, A. W., Nixon, C. L., Wilson, A. G., \& Capage, L. (1999). Social interaction skills and theory of mind in young children. Developmental Psychology, 35, 386-391.

Cummings, E. M., Simpson, K. S., \& Wilson, A. (1993). Children's responses to interadult anger as a function of information about resolution. Developmental Psychology, 29, 978985.

\section{PRESENTATIONS}

Wilson, A. (1999, April). Theory of Mind and Attentional Processes in Elementary School Children. Poster presented at a meeting of the Society for Research in Child Development, Albuquerque, New Mexico.

Watson, A., Nixon, C., Wilson, A., \& Capage, L. (1999, April). Individual Differences in Social Interaction Skills and Theory of Mind. Poster presented at a meeting of the Society for Research in Child Development, Albuquerque, New Mexico.

Wilson, A. (1998, March) Theory of Mind and Self-Regulation in Young School Children. In Anne Watson O'Reilly (Chair) Individual Differences in "Mindreading" and Correlations in the Social Domain. Symposium submitted to the meeting of the Southwestern Society for Research on Human Development, Galveston, TX.

Wilson, A. (1997, May). Mindreading in Preschoolers. Paper presented in a symposium at the meeting of the Association for Behavior Analysis, Chicago, IL. 
O'Reilly, A. W., Nixon, C. L., \& Wilson, A. G. (1995, June). Relations between social interaction and "theory of mind" ability in preschoolers. Paper presented at the Symposium of the Jean Piaget Society, Berkeley, CA.

Cummings, E.M., Simpson, K., Wilson, A., \& Pennington, L. (1993, March). Fighting constructively: Children's reaction to everyday contexts of interpersonal conflict resolution. In E. M. Cummings (Chair), Contexts of interparental conflict and child behavior. Symposium conducted at the meeting of the Society for Research in Child Development, New Orleans, LA.

\section{WORKSHOPS PRESENTED}

"Developmentally Appropriate Discipline." Parent seminar presented at Mountainview Elementary School (March 1997).

"Social Development: Age 5 to 15." Parent seminar presented at Mountainview Elementary School (January 1997).

"Identifying and Coping with Aggression in Your Child." Parent-education workshop at Mountainview Elementary School (November, 1994; October, 1995; October 1996).

"Managing Childhood Anger." Parent seminar presented at Mountainview Elementary School (March 1995)

"The Impact of Marital Conflict on Children's Coping." Parent seminar presented at Mountainview Elementary School (April, 1993).

"Controlling Adolescent Aggression." Training seminar presented at Odyssey House (November, 1995).

"Stress and Adjustment to College." Presented to students involved with Student Support Services at West Virginia University (September 1994, September 1995).

"Time Management: How to Get A's and Still Have Some Fun." Presented to students involved with Student Support Services at West Virginia University (November 1994, February 1996).

"Effective Communication: How to Be Heard." Presented to students involved with Student Support Services at West Virginia University (March 1995, April 1996). 


\section{VOLUNTEER ACTIVITIES}

Teacher, Elementary School Bible Study Group, First Presbyterian Church, Clarksburg, WV, September 1997 to June 1998.

Special Olympics, Clarksburg and Morgantown, WV, September 1983 to May 1994.

Pediatric Ward, WVU/Ruby Memorial Hospital, September 1987 to May 1991.

\section{HONORS AND ACTIVITIES}

Member West Virginia University Honors Program

Member Phi Beta Kappa Honorary

Member Phi Kappa Phi National Honorary

Member Mortar Board and Golden Key National Honor Societies

Member Alpha Phi Omega (secretary and membership committee)

Member American Psychological Association

Member Society for Research in Child Development

Member Psi Chi Honorary

Arts and Sciences Scholarship

Arts and Sciences Scholar

Presidential Scholarship - WVU

Member Full Faculty Committee - Psychology Department, WVU (2 years)

Member Undergraduate Training Committee - Psychology Department, WVU

Member Interview Weekend Committee - Psychology Department, WVU

Member Colloquium Host Committee - Psychology Department, WVU 